\title{
ESCOLHA MANUAL, SELEÇÃO ELETRÔNICA PELA COR, TRATAMENTO FUNGICIDA E QUALIDADE DE SEMENTES DE AMENDOIM (Arachis hypogaea L.)
}

\section{CASSIO EGIDIO CAVENAGHI PRETE}

Orientador: Prof. Dr. SILVIO MOURE CICERO

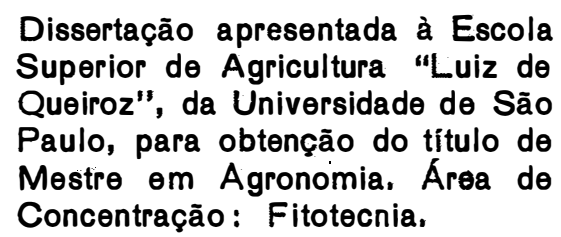

PIRACICABA

Estado de São Paulo - Brasil

Março - 1985 
ii:

A CRISTINA, minha esposa, e aos filhos THOMAS, LIGIA $e$ FERNANDO, com amor.

DEDICO. 


\section{AGRADECIMENTOS}

Ao professor Dr. SILVIO MOURE CICERO, pelo estímulo e dedicada orientação;

Aos professores Dr: Jūlio Marcos Filho e Dr. José Otávio Machado Menten pelas críticas e sugestões apresentadas;

Aos professores Drs. Décio Barbin, pelo planejamento da análise estatística e Evoneo Berti Filho pela versao do resumo ao inglês;

A Fundação Universidade Estadual de Londrina e aos colegas do Departamento de Agronomia pela oportunidade para realização desse Curso;

A firma "Sementes Contibrasil Ltda." pela doação das sementes e utilização de sua unidade de beneficiamento de sementes;

A colega Yurika Helena Komatsu e àos. funcionários do Departamento de Agricultura e Horticultura da E.S.A. "Luiz de Queiroz"; pelos auxílios na instalação dos experimentos;

Ao prof. Dr. Francisco Ferraz de Toledo pelas facilidades proporcionadas para a utilização da unidade de beneficiamento de sementes do D.A.H./ESALQ/USP e para a execução dos testes de campo;

A todos os colegas com os quais convivi no período de realização desse curso e ao sentimento de amizade e respei to que permanece apesar da distância;

Ao colega Jorge Luiz Diorio pelos serviços datilográ ficos;

A CAPES/PICD pela bolsa de estudo concedida;

A Escola Superior de Agricultura "Luiz de Queiroz", pelas facilidades proporcionadas para a realização desse curso. 


\section{INDICE}

Pāgina

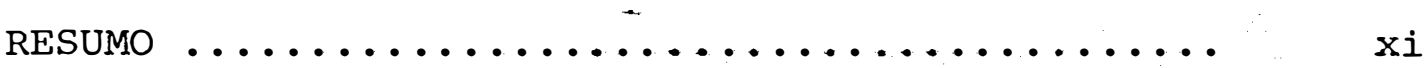

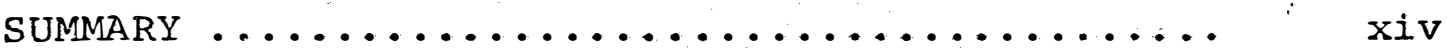

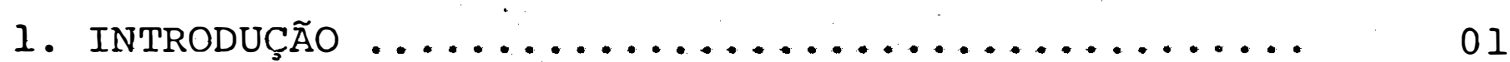

2. REVISÃo DE LiteraturA ................... 03

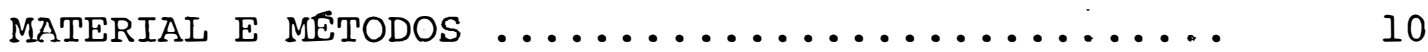

3.1. Etapas do beneficiamento .............. 10

3.1.1. Selecionadora eletrônica........... 11

3.1.2. Seleção eletrônica .............. 13

3.1.3. Escolha manual ................. 14

3.1.4. Escolha manual seguida de seleçãoele

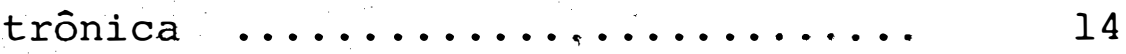

3.1.5. Tratamento fungicida ............ 15

3.1.6. Tratamentos ................. 15

3.2. Testes realizados para avaliação da qualidą

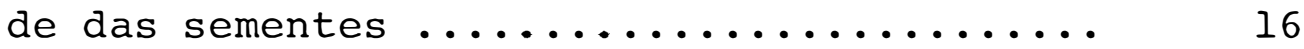

3.2.1. Análise de pureza física ......... 17

3.2.2. Exame de sementes com tegumento danificado .................. 17

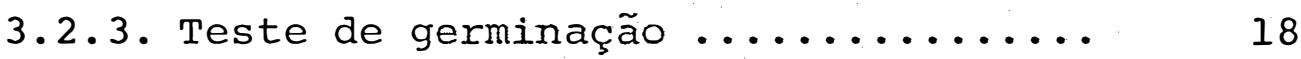

3.2.4. Envelhecimento acelerado ......... 18

3.2.5. Emergência em areia ............ 19

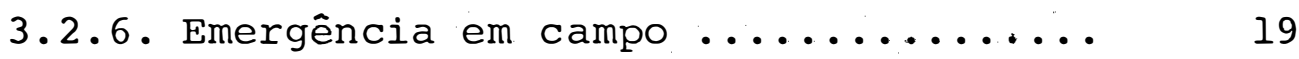

3.2.7. Exame de sanidade das sementes ..... 20

3.2.8. Grau de umidade ............... 21

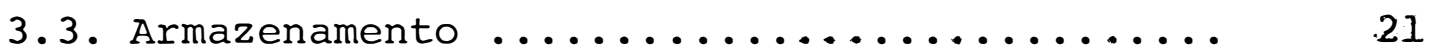

3.4. Procedimento estatístico .............. 21 
4. RESULTADOS ........................

4.1. Anālise de pureza física ..............

4.2. Exame de sementes com tegumento danificado.

4.3. Teste de germinação .................

4.4. Envelhecimento acelerado

32

4.5. Emergência em areia ..............

36

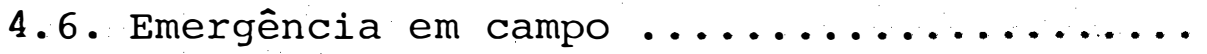

39

4.7. Exame de sanidade das sementes

40

45

5. DISCUSSÃo $\ldots \ldots \ldots \ldots \ldots \ldots \ldots \ldots \ldots \ldots \ldots \ldots \ldots \ldots \ldots \ldots \ldots \ldots$

CONCLUSÕES $\ldots \ldots \ldots \ldots \ldots \ldots \ldots \ldots \ldots \ldots \ldots \ldots \ldots \ldots \ldots \ldots \ldots$

LITERATURA CITADA $\ldots \ldots \ldots \ldots \ldots \ldots \ldots \ldots \ldots \ldots \ldots \ldots \ldots$

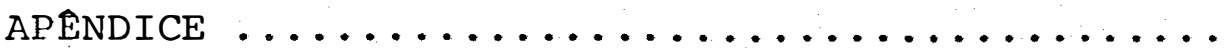

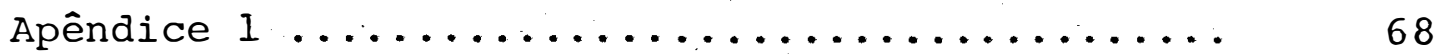

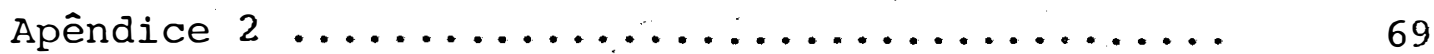

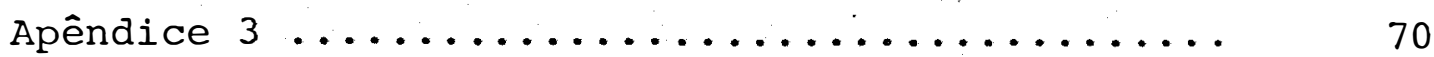

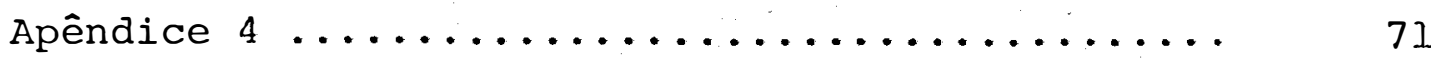

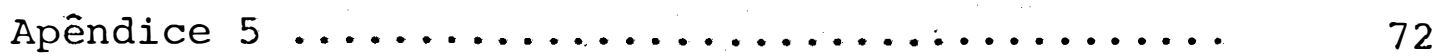

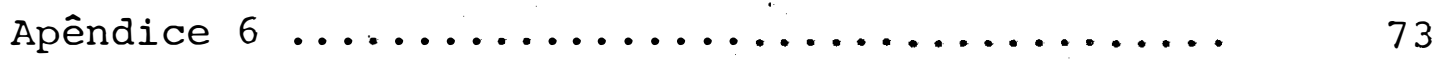


vi.

\section{IISTA DE TABELAS}

TABELA NO

Página

01 Esquema utilizado para a análise de variância dos dados obtidos para o teste de análise de pureza física e exame de sementes com tegumento danificado .....

02 Esquema utilizado para a análise de variância dos dados obtidos para o teste de germinação, envelhecimento acelerado e emergência em areia .............

03 Esquema utilizado para a análise de variância dos dados obtidos para o teste de emergência em campo ............

04 Valores de F para efeito dos métodos de beneficiamento nos testes realizados nas respectivas épocas de análise ........

05 Valores de F para efeito do tratamento fungicida nos testes realizados nas res pectivas épocas de análise ..........

06 Valores de $\mathrm{F}$ para efeito da interação mê todos de beneficiamento xtratamento fun gicida nos testes realizados nas respec tivas épocas de anālise ............. 
Análise de pureza física: médias obtidas para o efeito de beneficiamento (da dos originais em $\%$ e dados transformados em arc sen $\sqrt{x / 100}$ em graus), dife rença mínima significativa ao nível de 5\% de probabilidade e coeficiente de va

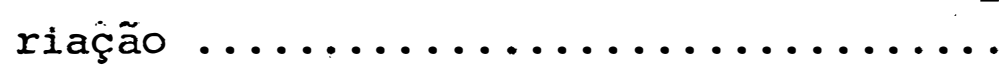

Exame de sementes com tegumento danificado: médias obtidas para efeito do beneficiamento (dados originais em $\%$ e da dos transformados em arc sen $\sqrt{\mathrm{x} / 100}$ em graus) diferença mínima significativaao nível de 5\% de probabilidade e coefici-

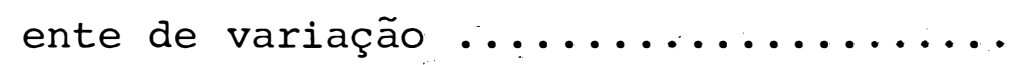

09 Teste de germinação: médias obtidas para o efeito de métodos de beneficiamen to (dados originais em $\%$ e dados transformados em arc sen $\sqrt{\mathrm{x} / 100} \mathrm{em}$ grausl, diferença mínima significativa ao nível de 5\% de probabilidade e coeficien te de variação nas três épocas de análí

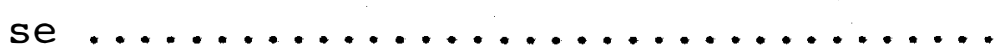

10 Teste de germinação: médias obtidas para o efeito do tratamento fungicida (dâ dos originais em $\%$ e dados transfonmados - em arc sen $\sqrt{\mathrm{x} / 100}$ em graus), diferença mínima significativa ao nível de $5 \%$ de probabilidade e coeficiente de variação nas trếs épocas de análise .......... 
viii.

TABELA NO

Pāgina

11 Teste de germinação: médias obtidas para o efeito da interação tratamento fun gicida dentro de métodos de beneficiamen to (dados originais em $\%$ e dados transformados em arc sen $\sqrt{\mathrm{x} / 100} \mathrm{em}$ graus), diferença mínima significativa ao nível de 5\% de probabilidade e coeficiente de variação na 3a. época de análise ......

12 Teste de germinação: médias obtidas para o efeito da interação métodos de beneficiamento dentro de tratamento fungi cida (dados originais em $\%$ e dados trans formados em arc sen $\sqrt{x / 100}$ em graus), diferença mínima significativa ao nível de 5\% de probabilidade e coeficiente de variação na 3a. época de análise .....

13 Envelhecimento acelerado: médias obtidas para o efeito de métodos de beneficiamento (dados originais em $\%$ dados transformados em arc sen $\sqrt{\mathrm{x} / 100}$ em graus), diferença mínima significativa ao nível de 5\% de probabilidade e coeficientes de variação, nas três épocas

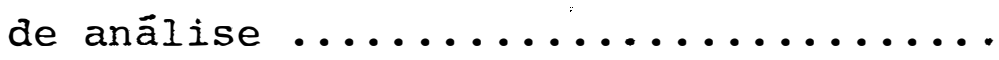

14 Envelhecimento acelerado: médias obtidas para o efeito de tratamento fungici da (dados originais em $\%$ e dados transformados em arc sen $\sqrt{x / 100}$ em grausl, diferença mínima significativa ao nível de 5\% de probabilidade e coeficiente de variação nas três épocas de análise.. 
TABELA NQ

15

Emergência êm areia: médias obtidas para o efeito de tratamento fungicida (da dos originais em $\%$ e dados transformados em arc sen $\sqrt{\mathrm{x} / 100}$ em graus), diferen ça mínima significativa ao nível de $5 \%$ de probabilidade e coeficiente de varia ção nas trẽs épocas de anālise .......

16 Emergência em campo: médias obtidas para o efeito de métodos de beneficiamen to (dados originais em $\%$ e dados transformados em arc sen $\sqrt{x / 100}$ em graus), diferença mínima significativa ao nivel de 5\% de probabilidade e coeficien te de variação nas três épocas de anā-

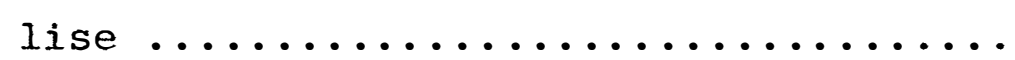

17 Emergência em campo: médias obtidas para o efeito de tratamento fungicida (da dos originais em $\%$ e dados transformados em arc sen $\sqrt{x / 100}$ em graus), diferen ça mínima significativa ao nível de $5 \%$ de probabilidade e coeficiente de varia ção nas três épocas de anālise .......

18 Emergência em campo: médias obtidas para o efeito da interação tratamento fun gicida dentro de métodos de beneficjamen to (dados originais em $\%$ e dados transformados em arc sen $\sqrt{x / 100}$ em graus), diferença mínima significativa ao nível de $5 \%$ de probabilidade e coeficiente de varia ção na la. época de anālise .......... 
Emergência em campo: médias obtidas para o efeito da interação métodos de beneficiamento dentro de tratamento fungi cida (dados originais em $\%$ e dados trans formados em arc sen $\sqrt{\mathrm{x} / 100} \mathrm{em}$ graus), diferença mínima significativa ao nível de 5응 de probabilidade e coeficiente de variação na la. época de anālise ......

Exame de sanidade das sementes: ocorrên cia média de Penicillium spp. Aspergillus spp e Rhizopus sp. (Dados originais

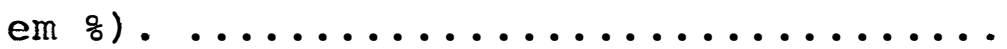


ESCOLHA MANUAL, SELEÇÃO ELETRONICA PELA COR, TRATAMENTO FONGICIDA E QUALIDADE DE SEMENTES DE AMENDOIM (Arachis hypogaea I.)

\author{
Candidato: CASSIO EGIDIO CAVENAGHI PRETE \\ Orientador: Prof. Dr. SILVIO MOURE CICERO
}

RESUMO

Este trabalho foi conduzido no Departamento de Agricultura e Horticultura da Escola Superior de Agricultura "Luiz de Queiroz", da Universidade de são Paulo (DAH/ESALQ/ USP), Piracicaba, SP, no período de agosto de 1982 a julho de 1983. Teve como objetivo obter informações sobre o efeito da escolha manual, da seleção eletrônica pela cor e do tratamento fungicida sobre a qualidade de sementes de amendoim e desse modo contribuir para o aprimoramento dos métodos de manuseiovi sando dbtençãode sementes de amendoim de boa qualidade física, fisiológica e sanitária.

o lote de sementes de amendoim em casca foi sub metido a un descascador dotado de peneira circular vibratória; em seguida a massa de sementes foi classi ficada pela largura, separando-se as retidas na peneira 22/64"; estas, a seguir, foram submetidas a mesa gravitacional, sendo que as sementes da fração mais pesada constituiram o material original, do qual derivaram-se os outros tra 
tamentos do presente trabalho, a saber: material original não catado; material com uma seleção eletrônica; material com duas seleções eletrônicas, material com três seleções eletrônicas, material catado manualmente ( 8 pessoas), material catado manualmente ( 4 pessoas) seguido de uma seleção eletrônica; e, finalmente, material descartado pela selecionadora eletrônica. Todos os tratamentos foram divididos e uma porção recebeu tratamento com o fungicida Thiran na dose $2 \mathrm{~g}$ do i.a. por $\mathrm{kg}$ de sementes e a outra permaneceu sem tratamento fungicida.

Os diversos tratamentos foram armazenados em condições ambientais do Laboratório de Análise de Sementes do $\mathrm{DAH} / \mathrm{ESALQ/USP}$ e trimestralmente (outubro, janeiro e abril) fo ram retiradas amostras para as análises.

Para avaliar a qualidade física foram conduzidos os testes de análise de pureza e exame de sementes com tegumento danificado; para determinar a qualidade fisiológica, os testes de germinação, envelhecimento acelerado, emergência em areia e emergência em campo e,para avaliar a qualida de sanitária, o exame de sanidade das sementes.

Nas condições em que foi realizado o trabalho concluiu-se que: as sementes descartadas pela selecionadora eletrônica, compostas predominantemente de sementes de amendoim de coloração mais clara e mais escura que a cor característica da cultivar e de sementes com tegumento danificado expondo o embrião, foram de menor qualidade física, fisiológica e sanitária; entretanto, a remoção destes materiais através da 
xiii.

escolha manual e/ou seleção eletrônica melhorou apenas a qualidade física e não alterou a qualidade fisiológica e sanitária do lote de sementes de amendoim. o tratamento fungicida beneficiou a qualidade fisiológica e sanitária das semen tes e exerceu efeito protetivo no momento da semeadura. 
xiv.

\title{
INFLUENCE OF THE HAND PICKING, ELECTRIC COLOR SORTING AND FUNGICIDE TREATMENT METHODS ON SEED QUALITY OF PEANUTS (Arachis hypogaea I.)
}

\author{
Author: CASSIO EGIDIO CAVENAGHI PRETE \\ Adviser: Prof. Dr. SILVIO MOURE CICERO
}

\section{SUMMARY}

This research was carried out at the Department of Agriculture and Horticulture of "Escola Superior de Agricultura Luiz de Queiroz", University of são Paulo in Piracica ba, State of Sao Paulo, Brazil, from August 1982 to July 1983. The objective was to collect information concerning theeffects of hand picking, electric color sorting and fungicide treatment on the quality of peanuts seeds, in order to obtain healthy seeds of good physical and physiological quality. The peanut seeds were processed in a sheller with vibratory circular screen; following this operation the mass of seeds was classified and the seeds were retained on the $22 / 64 "$ screen. Then the seeds passed through a gravity table, were the heaviest ones were separated to be used in the differents treatments. The treatments were the follows: 1. the original material (check), 2. material submitted to one electric sorting, 3. material submitted to two electric sortings, 4. material submitted to three electric sortings, 5. hand picking by 8 
persons, 6 . hand picking by 4 persons followed by an electric sorting, 7. material rejected by the electric sorting.

All the treatments were divided in two parcels and one of each was treated with the fungiciale thiran ( $2 \mathrm{~g}$ of active ingredient per kilogram of seeds). The parcels were kept in the laboratory and samples were taken from each parcel every three months (October, January and April). Purity analysis and presence of seeds with damage tegument were used to check the physical quality of seeds. While germination test, accelerated aging and emergency of seedlings in the sand and in the field were used to check the physiological quality. Seed health was check by direct observation of the material after incubation ( $20 \pm 29 \mathrm{C}, 12$ hours photoperiod) for seven days. The results have indicated that the seeds rejected by the electric sorting (seeds which color was lighter or darker than the characteristics color of the cultivar, and seeds with damaged tegument with exposed embryo) had the lowest physical, physiological and health qualities. However the hand picking or the electric sorting methods improved only the physicalquality and did not change the physiological and health qualities of the seeds. The treatments using fungicide improved the physiological and health qualities of the seeds. 


\section{INTRODUÇÃO}

A produção de amendoim (Arachis hypogaea L.) no Brasil tem decaído através dos anos, sendo vários os fatores negativos que influem nesta tendência de queda, destacando-se: a instabilidade da política agrícola governamentalquan to aos estímulos ao cultivo do amendoim; a baixa produtividade em alguns anos, devido as adversidades climáticas; a varia ção sensível nos preços, principalmente, quando da comercialí zação; a escassez, em alguns anos, de sementes de boa qualida de e os preços cada vez mais elevados destas sementes, que en carecem o custo de produção (GODOY et alii, 1982).

Com relação às sementès de amendoim, estas podem apresentar, muitas vezes, baixa qualidade fisiológica devido às suas características químicas de riqueza em óleo e pro teína, a sensibilidade a danos mecânicos e às condições de cultivo, manuseio e armazenamento reinantes no Brasil.

Dentre as técnicas de manuseio para a obten- 
ção de lotes de sementes de amendoim, as firmas produtoras uti lizam corriqueiramente a escolha manual, onde é feita a retirada de sementes com coloração mais escura e mais clara que a cor característica do cultivar, sementes sem tegumento, semen tes partidas e outros materiais indesejáveis, visando elevar a qualidade física e fisiológica dos lotes de sementes. Outra possibilidade seria a utilização da selecionadora eletrônica em substituição à escolha manual; entretanto, são raros os tra balhos conduzidos com a finalidade de avaliar a necessidade e eficiência desses métodos de beneficiamento. Já o tratamento fungicida das sementes de amendoim é assunto bastante estudado esua utilização é obrigatória porque as sementes dessa oleaginosa, em função das condições predominantes durante a produção, apresentam sérios problemas relacionados a sanida de (BRASIL, M.A., CESM-CEPROSEM, 1983).

Buscando-se obter informações para a produção de sementes de amendoim de boa qualidade, objetivou-se neste trabalho comparar o beneficiamento de sementes sem catação, com a catação manual e com a seleção eletrônica e os efeitos do tratamento fungicida das sementes após os diferentes métodos de beneficiamento. 
3.

\section{REVISÃO BIBLIOGRÁFICA}

Na literatura são encontrados poucos trabalhos sobre beneficiamento de sementes de amendoim, não obstante, é grande o número de trabalhos a respeito do tratamento fungicida de sementes de amendoim. Assim, BACCHI e CANECCHIO FILHO (1954), ZINK et alii (1962), TOLEDO e GRANER (1963); CAMPACCI e SILVEIRA FILHO (1964) y BELL (1968), LAGO e TOLEDO (1970), CARTER (1973), BELL (1974), BACKMAN e HAMMOND (1976), LAGO et alii (1976), TELLA et alii (1976), SILVEIRA e MARIOTTO (1979), HAM MONS (1980), MARIOTTO et alii (1982), conduziram experimentos e verificaram ser o tratamento fungicida de sementes de amendoim um fator de fundamental importância para proteger sua sanidade.

A necessidade de realizar o descascamento mecâa nico para produção racional e em larga escala de sementes de amendoim tornou as danificąções mecânicas sofridas pelas sementes um fator de suma importância tendo em vista que o frá- 
gil tegumento do amendoim oferece pouca proteção contra danos mecânicos, assim, BACCHI e CANECCHIO FILHO (1954), ZINK et alii (1962), BASKIN e DELOUCHE (1971) verificaram que as dani ficações mecânicas afetavam a longevidade das sementes. Trabalhos de LAGO et alii (1976), TELLA et alii (1976), BACKMAN e HAMMOND (1976) comprovaram o efeito do tratamento fungicida aumentando a longevidade de sementes de amendoim.

CARTER (1973) e BELL (1974) estudaram o efeito da interação danos mecânicos e infecção das sementes por fungos e observaram que quanto maior a porcentagem de danos mecânicos, maior a infecção das sementes por fungos e menor é a emergência das plântulas de amendoim. CARTER (1973) observou, também, que o tratamento fungicida das sementes aumentava a porcentagem de emergência das sementes danificadas ao nível das sementes não danificadas mecanicamente.

TANGO et alii (1971/72) observaram a predominância de fungos do gênero Rhizopus sp. com presença também de Aspergillus spp., em grãos de amendoim armazenado em ambientes com umidade relativa do ar variando de $10 \%$ a $100 \%$.

Apesar do grande número de trabalhos comprovan do a eficiência do tratamento fungicida de sementes de amendoim poucos são os trabalhos no qual houvesse um levantamento e identificação dos patógenos que infectavam as sementes antes e após o tratamento fungicida, neste sentido; MARIOTTO et alii (1982) conduziram experimento onde identificaram os fungos que ocorriam em sementes de amendoim em testes de labo 
ratório e em campo, destacando pela frequência o gênero $R$ hizopus no laboratório e em campo o fungo Rhizoctonia; verificaram ainda que dos fungicidas testados o mais eficiente foi - Thiran na dose de $3 \mathrm{~g}$. do produto comercial Rhodiauran/kg de sementes.

Levantamento e identificação dos fungos associados à sementes de amendoim foram realizados por DIENER (1960) que destacou o gênero Aspergillus como o mais frequente; NAKAMURA e NISHIMURA (1974) encontraram os gêneros Aspergillus e Rhizopus como os mais frequentes, MERCER e KISYOMBE (1978) destacaram na flora füngica associada a sementes de amendoim os fungos Aspergillus niger, A. Glavus, Macrophomina phaseolina, Fusarium spp. e Penicillium spp.

AMARAL e USBERTI (1983) detectaram os fungos Aspergillus flavus, Aspergillus niger, Penicillium spp e Rhizopus sp. em trabalho que comparava sementes de amendoim armazenadas sem tratamento e com o tratamento a base do produto comercial Auralin (Thiran 70\% + 1\%BHC), observaram, tambēm a menor infeç̧ão das sementes tratadas em relação às não tratadas.

MORAES E MARIOTTO (1984) realizaram um diagnós tico da patologia de sementes de amendoim no Brasil e destacaram,pela frequência de ocorrência nas sementes, os fungos As pergillus spp, Penicillium spp, Rhizopus sp., Fusarium spp, Macrophomina phaseolina e Rhizoctonia solani.

LIMA et alii (1984) verificaran haver uma corre- 
lação negativa entre a abundância dos fungos A.spergillus spp e Rhizopus sp. nas sementes e a porœntagem de germinação e vigor das sementes de algodoeiro.

A presença de patógenos infectando sementes e provocando alterações em características físicas da semente de amendoim é conhecida e ilustrada por trabalhos como os de GARREN e HIGGINS (1947), WILSON (1947), GARREN et alii (1947), GILLIER e SILVESTRE (1970). KIMATI (1980) cita que sementes de amendoim afetadas por Rhizoctónia solani não se desenvolvem bem, são menores, enrugadas e com coloração mais clara que a cor caracteristica da cultivar.

WATZ (1928) cita que, em determinados casos, características subjetivas ou externas como a cor das sementes podem auxiliar a conhecer $\circ$ valor das sementes e embora não sejam suficientes, são grandes auxiliares para o diagnóstico de uma prova de sementes. Assim, CASTRO (1932) relaciona a cor das sementes com sua qualidade recomendando que se utilize sementes de amendoim provenientes das vagens quefi cam no centro da planta e que não se utilize para semeadura, sementes de amendoim que tenham a película cor vermelho vinho sa. EASTMAN (1912), DYAMOND (1920), Vaughan (1962) citadopor BOYD et alii (1968) e DELOUCHE (1965) mostraram haver correla ção entre a cor e a viabilidade de sementes de trevo.

O relacionamento da má qualidade sanitária e fisiológica das sementes com seu menor tamanho e densidade, enrugamento, descoloração e/ou presença de manchas, as quais 
são sintomas da presença de patógenos é exemplificada na lite.. ratura pelos trabalhos de VIEIRA (1967), MENTEN et alii (1977), MENTEN et alii (1979), GOMES e DHINGRA (1980) e GALLI et alii (1983) com feijão; FURLANI et alii (1975) com arroz; ALMEIDA e MACHADO (1979), ALMEIDA e MIRANDA (1979) e YORINORI (1982) com soja; MEHTA (1978) com trigo. Sementes com essas alterações nas características físicas podem ser separadas e eliminadas durante o beneficiamento con forme NEERGAARD (1977) e com isso aumentar a qualidade fisiológica e sanitária de um lote de sementes de acordo com SMIT TLE et alii (1976), NEERGAARD (1977) e LOLLATO e SILVA (1981). O efeito da escolha manual de sementes de feijão sobre a qualidade fisiológica foi estudado por ALMEIDA et alii (1980) que verificaram significativo aumento nas porcentagens de germinação e emergência e na produção quando se procedeu a escolha manual das sementes. MENEZES e MOHAN(1982) observaram significativo aumento na sanidade das sementes de feijão quando se procedeu a catação manual das sementes manchadas, enrugadas, danificadas e mal formadas.

BRADENBURG e PARK (1977) descrevem os princípios de operação das seletoras eletrônicas pela cor utilizadas no beneficiamento de sementes e destacam algumas vantagens da máquina em relação à escolha manual, entre elas a de detectar diferenças de cor ou luz não detectadas pelo olho humano, a de observar a semente em todos os lados simultaneamente e de poder operar continuamente produzindo um lote de 
sementes cujas cores ou sombras são essencialmente constantes. BOYD et alii (1968) estudaram aiversas possibilidades de aplicações da selecionadora eletrônica na área de beneficiamento de sementes e comprovaram sua eficiência na melhoria das características físicas e fisiológicas de lotes de sementes, destacaram ainda a versatilidade e precisão da seleciona dora eletrônica e citaram como desvantagens o alto custo, bai xa capacidade e a necessidade de um treinamento especializado para operar adequadamente o equipamento.

DICKENS e WHITAKER (1975) estudaram a eficiência da separação eletrônica pela cor e da escolha manual sobre a remoção de grãos provenientes de lotes comerciais de amendoim contaminados com aflatoxina, verificaram uma diminui ção cumulativa nos níveis de aflatoxina com o aumento do número de passadas dos lotes de grãos de amendoim pela máquina, embora os resultados fossem variáveis conforme os lotes.

$$
\text { LIMA NETO e COSTA (1976) observaram a efí }
$$

ciência da selecionadora eletrônica na remoção de sementes de soja com mancha café.

CUNHA E OLIVEIRA (1978) e CUNHA (1979) verificaram efeito significativo da seleção eletrônica na sanidade e rendimento do feijoeiro, observaram ainda que o melhor resultado foi obtido quando submeteram o lote de sementes a duas catações eletrônicas e que o tratamento fungicida realizado não exerceu nenhum efeito sobre a sanidade e produção do feijoeiro. 
LIMA (1980) estudou os efeitos da catação eletrônica pela cor e do tratamento fungicida sobre a qualidade de sementes de feijão cv. Rosinha G-2 verificando que a seleção eletrônica foi eficiente na remoção de sementes portadoras de manchas sobre o tegumento; observou, ainda,que as semen tes descartadas pela máquina foram sempre de qualidade inferior e que somente uma catação eletrônica foi suficiente para a remoção dos contaminantes indesejāveis, não havendo efeito do número de catações e do tratamento fungicida sobre a quali dade das sementes. 
10.

\section{MATERIAL E METODOS}

O trabalho foi desenvolvido na Usina de Beneficiamento de Sementes, no Laboratório de Análise de Sementes e em condições de campo do Departamento de Agricultura e Horticultura da Escola Superior de Agricultura "Luiz de Queiroz", da Universidade de São Paulo (D.A.H./ESALQ/USP) em Pira cicaba, SP, tendo sido iniciado em 01/08/82.

As sementes de amendoim cultivar Tatú vermelho utilizadas no presente trabalho, foram produzidas na região de Guararapes - São Paulo, durante a safra das áquas 1981/82 e foram obtidas junto a firma "Sementes Contibrasil Ltda".

\subsection{Etapas do Beneficiamento}

As sementes de amendoim, apōs a colheita foram armazenadas em casca, embaladas em sacos de juta e assim permaneceram até a época do beneficiamento. 
Inicialmente as vagens foram descascadas em descascador de marca BLASI dotado de peneira circular vibratō ria (sururuca) para separação das cascas. A seguir a massa de sementes foi submetida a separação por peneiras, em classí ficador de peneiras da marca BLASI.

As peneiras obtidas foram: pen 23, pen 22, pen 20 e pen 19. As sementes da pen 22 foram a seguir beneficiadas em uma mesa gravitacional da marca Casp-Matic e as sementes mais pesadas, da porção superior da extremidade de descar ga da mesa, foram reunidas e constituiram-se no material original do qual derivaram-se os 14 tratamentos do presente trabalho.

\subsubsection{Selecionadora eletrônica}

A catação eletrônica foi feita por uma selecionadora eletrônica modelo SM-500 de fabricação nacional, per tencente ao D.A.H./ESALQ/USP. Esta selecionadora eletrônica faz a separação pelo processo de comparação cromática, separando aquelas sementes que apresentem cores indesejáveis. Seu funcionamento pode ser resumido da seguinte maneira: as sementes a selecionar, depositadas na tremonha alimentadora da máquina, são encaminhadas por um vibrador eletromagnético a uma correia transportadora dotada de velocidade linear constante. A disposição e a velocidade da correia trans portadora são tais que as sementes nela se enfileiram uma após a outra. Ao fim da correia, as sementes 
caem no interior de uma camara de análise, esta, intensamente iluminada, incorpora duas objetivas óticas e dois fundos de. referência sendo a semente inspecionada pelas objetivas contrá os fundos de referência. O contraste da semente com o fundo de referência, traduzido em termos de quantidade de luz, é enviado pelo sistema ótico da objetiva à célula fotoelétrica. Esta,impressionada pela luz, emite um sinal correspondente ao contraste observado, sinal este que é amplificado e dirigido a um circuito eletrônico, o qual determinará se a semente examinada deverá prosseguir em sua trajetória normal ou será expulsa. Caso deva ser expulsa a decisão é comunicada ao circuito de retardo que retém o sinal até que a semente atinja a saída da câmara. Após esse tempo,o sinal é passado ao circuito das ejetoras o qual providencia o aciona mento da válvula eletromagnética encarregada da expulsão das sementes indesejáveis. A ejetora desvia a semente defeituosa de sua trajetória normal encerrando-se aí o ciclo da operação.

A regulagem da selecionadora foi feita da seguinte maneira:

a) fundo de contraste: 225

b) vazão: 3

c) potenciômetro de sensıbilidade não atenuado

d) pressão do ar: 47 libras/pol ${ }^{2}$ para as ejetoras

e) seleção de claros e escuros foram utilizados simultanemente, pennitindo respectivamente, a separação e descarte de materiais com coloração mais escura ou mais clara que o desejado. 
f) Regulagens individuais

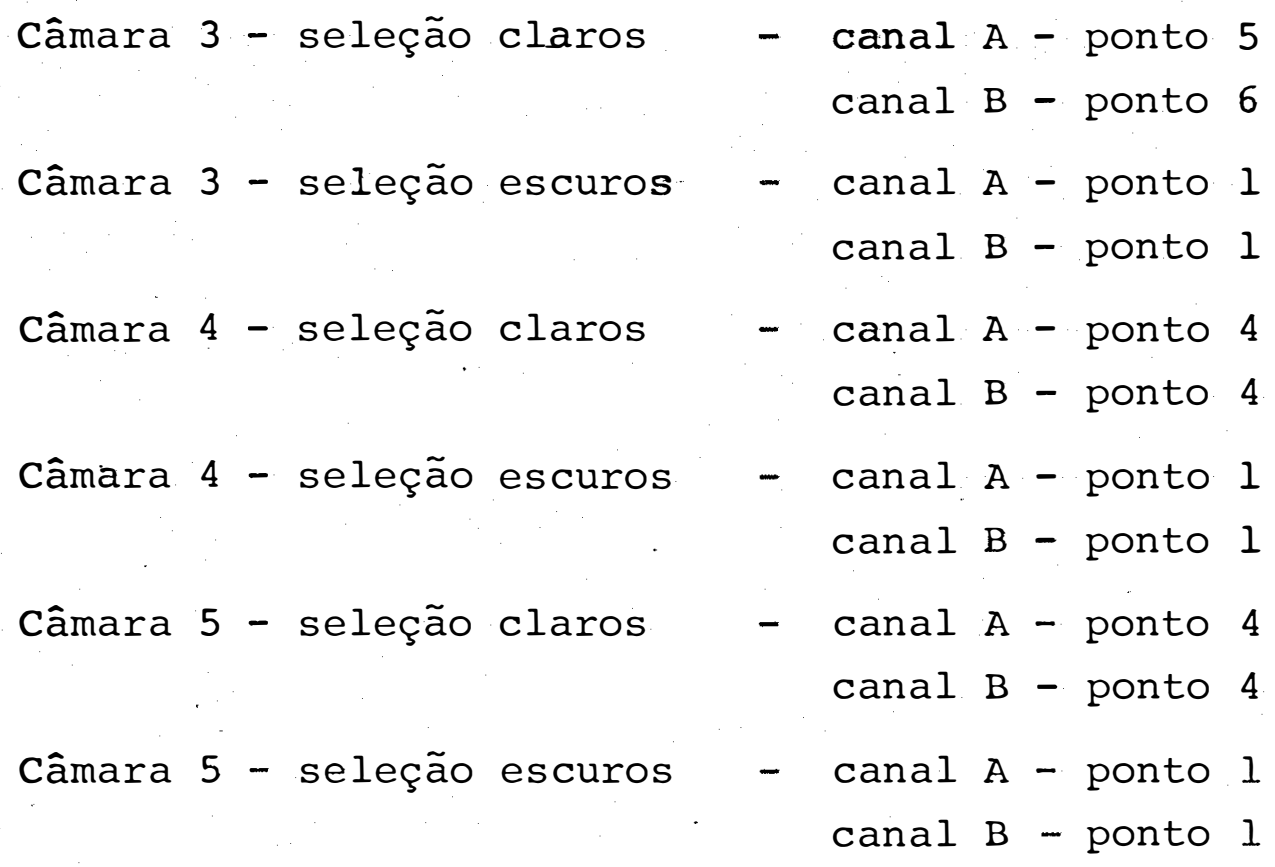

g) rendimento de trabalho: $310,6 \mathrm{~kg} / \mathrm{hora}$

h) percentagem média de sementes descartadas após a primeira seleção eletrônica: 7,5\%-

As regulagens foram realizadas por tentativas, e separaram-se como materiais descartados, sementes de coloração mais clara e mais escura que a cor característica da cultivar e aquelas com danificações mecânicas que expunham o embrião.

\subsubsection{Seleção eletrônica}

Apōs a limpeza, classificação e separação por peso, as sementes que constituiram-se no material original des te trabalho foram pesadas e, deste material homogeneizado, fo- 
ram separadas quatro porções de aproximadamente $5 \mathrm{~kg}$ cada uma para se constituir a testemunha ou material original. Quatro porções de $25 \mathrm{~kg}$ foram separadas para serem submetidas a seleção eletrônica e cada uma delas foi submetida respectivamen te a uma, duas e três seleções eletrônicas. Após cada seleção era retirada uma amostra de aproximadamente $5 \mathrm{~kg}$. Poste riormente as sementes descartadas nas três seleções foram reu nidas numa única amostra. Este ciclo de operação repetiu-se quatro vezes e desta forma foram sendo obtidas as repe tições.

3.1.3. Escolha manual

Uma outra porçao de $25 \mathrm{~kg}$ do material oriqinal foi submetida a escolha manual por oito pessoas, sendo este método de beneficiamento o comumente empregado pelas firmas produtoras de sementes de amendoim. A medida que o material era selecionado, no final da mesa de seleção coletava-se se paradamente quatro porções de aproximadamente $5 \mathrm{~kg}$ cada uma.

3.1.4. Escolha manual seguida de seleção eletrônica

Uma outra porção de $25 \mathrm{~kg}$ do material original foi submetida a escolha manual por 4 pessoas e, à medida que 
se processava a escolha, coletavam-se separadamente quatro porções de aproximadamente $5 \mathrm{~kg}$ cada uma. A seguir cada porção era submetida a apenas uma seleção eletrônica.

\subsubsection{Tratamento fungicida}

Após o beneficiamento, cada porção de $5 \mathrm{~kg}$ foi subdividida em duas porções iguais a $2,5 \mathrm{~kg}$ cada, sendo que uma das porções foi tratada com o fungicida Rhodiauram (70\% Thiran) na dose de $2 \mathrm{~g}$ do i.a. por $\mathrm{kg}$ de sementes.

\subsubsection{Tratamentos}

Assim, foram constituídos os seguintes tratamentos com 4 repetições:

01 - Material original (MO) (sem catação manual ou eletrônica), com e sem tratamento fungicida;

02 - Material com uma seleção eletrônica (1SE), com e sem tratamento funcida;

03 - Material com duas seleções eletrônicas $(2 \mathrm{SE})$, com e sem tratamento fungicida; 
04 - Material com três seleções eletrônicas (3SE), com e sem tratamento fungicida;

05 - Material escolhido manualmente por 8 pessoas (EM8), com e sem tratamento fungicida;

06 - Material escolhido manualmente por 4 pessoas seguida de uma seleção eletrônica (EM4+ISE), com e sem tratamento fungici$\mathrm{da}$;

07 - Descarte da selecionadora eletrônica (D), com e sem tratamento fungicida.

\subsection{Testes realizados para avaliação da qualidade} das sementes,

A avaliação da qualidade física e fisiológica das sementes de amendoim foi feita no laboratório de Análí se de Sementes e no campo experimental do D.A.H./ESALQ/USP. Os parâmetros determinados em laboratório foram: pureza física, sementes com tegumento danificado, germinação, envelhecimen to acelerado, emergência de plântulas em areia e sanidade das sementes. 
Em condições de campo foi avaliada a porcenta gem de emergência das plântulas aos 21 dias.

As determinações porcentagem de pureza física e porcentagem de sementes com tegumento danificado foram reali zadas apenas na primeira época, outubro de 1982. A determina ção da porcentagem de infeç̧ão das sementes por microrganismos foi realizada somente na última época, maio de 1983. As de mais determinações foram realizadas em três épocas a saber: outubro/novembro de 1982; janeiro/fevereiro de 1983 e abril/ maio de 1983.

\subsubsection{Análise de pureza física}

Das parcelas sem tratamento fungicida foi reti rada uma amostra de peso aproximado de $500 \mathrm{~g}$ após a homogène zação e subdivisão manual de cada parcela. Com esta amostra determinou-se a porcentagem de pureza física segundo as Regras para Análise de Sementes (BRASIL, M.A., 1976).

\section{3,2.2. Exame de sementes com tegumento danificado}

Na mesma amostra utilizada para a análise de pureza física foi realizada, através de um exame visual meti culoso das sementes puras, a separação daquelas que apresentavam os menores sinais de tegumento rompido. O material separacio foi pesado e 
obteve-se assim a porcentagem, em peso, de sementes puras com tegumento danificado.

\subsubsection{Teste de germinação}

O teste padrão de germinação foi realizado se gundo as Regras para Análise de Sementes (BRASIL, M.A., 1976L, empregando-se como substrato papel toalha especial de fabricação americana, sem lavagem prềvia, umedecido no momento da instalação dos testes. Foram semeados dois rolos com 50 sementes para representar cada repetição, a soma do número de plântulas normais observados nos dois rolos constituiu o valor médio representativo de cada repetição. O. teste foi rea lizado a temperatura constante de $25 \% \mathrm{C}$, procedendo--se a conta gem inicial no 49 dia devido a alta porcentagem de contaminação dos rolos quando não se fazia o tratamento das sementes e a seguir contava-se diariamente até concluir o teste.

\subsubsection{Envelhecimento Acelerado}

Neste teste as sementes foram submetidas às condições da câmara de envelhecimento acelerado marca DE LEO, a temperatura de $42.0 \mathrm{C}$ e $100 \%$ de umidade relativa por 48 horas (USBERTI, 1982); vencido o período de permanência na câmara, as sementes foram colocadas para germinar da forma descrita no item 3.2.3., e a interpretação foi realizada da mesma ma neira do teste de germinação. 


\subsubsection{Emergência em areia}

Utilizaram-se neste teste caixas plásticas com dimensões de $38 \mathrm{~cm} \times 28 \mathrm{~cm} \times 10 \mathrm{~cm}$ contendo como substrato areia lavada de rio. Colocaram-se $6 \mathrm{~kg}$ de areia por caixa plástica, fez-se a semeadura de 50 sementes e cobriu-se as sementes com uma camada de $2,5 \mathrm{~cm}$ de areia; a seguir acres centou-se água até atingir a capacidade de campo. A contagem foi feita no 10 Q dia após a instalação do teste, considerando-se emergida toda plântula que se apresentava com os cotilédones emergidos e as folhas primárias visíveis em seu interior.

Foram feitas 2 leituras (repetições) de 50 sementes por tratamento e por repetição e as caixas foram colocadas em condições ambientais do Laboratório de Análise de Se mentes do DAH/ESALQ/USP.

\subsubsection{Emergência em campo}

Para o teste de campo foram empregadas 2 repetições de 100 sementes, por parcela. As 100 sementes foram colocadas em sulcos, com cerca de $3 \mathrm{~cm}$ de profundidade, de 4 metros de comprimento e distanciados entre si de $0,30 \mathrm{~m}$. As semeaduras foram realizadas em solo Latossolo Vermelho Escuro, fase argilosa. Na ausência de chuvas os campos foram 
irrigados. No vigésimo primeiro dia após a semeadura, quando os cotilédones das plântulas encontravam-se secos fez-se a contagem das plântulas.

\subsubsection{Exame de sanidade das sementes}

o teste de sanidade foi realizado utilizando-se 50 sementes para cada repetição. Para tal, procedeu-se ao plaqueamento de 10 sementes por placa de petri plástica contendo 3 folhas de papel de filtro umedecido em ăgua destilada.

Após o plaqueamento as sementes permaneciam du rante 24 horas em câmara de incubação a temperatura de $20 \pm$ $20 \mathrm{C}$ e sob regime de 12 horas de luz fluorescente e 12 horas no escuro. Após este período as sementes foram retiradas da câmara de incubação e foram colocadas em congelador a -10 oc de temperatura durante 24 horas. Em seguida as sementes retornavam a câmara de incubação e ali permaneceram até se completarem 07 dias após a instalação do teste quando então foram feitas as leituras em microscópio estereoscópico.

Nos tratamentos sem fungicida foram feitas as avaliações sem assepsia superficial e com àssepsia superficial das sementes com hipoclorito de sódio ( $\mathrm{NaOCl}$ ) solução $1: 3$ durante 2 minutos. 


\subsubsection{Grau de umidade}

Determinado, nas três épocas de análise, pelo método da estufa, a 105\%C durante 24 horas, utilizando-se duas amostras por repetição, conforme as Regras para Análise de Se mentes (BRASIL, M.A., 1976).

\subsection{Armazenamento}

Após a etapa de beneficiamento, as sementes fo ram embaladas em sacos de papel kraft e, a seguir, armazenadas no período de outubro de 1982 a maio de 1983 em condições normais de ambiente, no Pavilhão de Sementes do DAH /ESALQ / USP.

A caracterização do ambiente de armazenamento foi posspivel através do registro diário da temperatura e umidade relativa do ar, em termohigrógrafo e os dados encontram-se nos apêndices 5 e 6 .

\subsection{Procedimento estatistico}

Os dados obtidos nos testes de análise de pure za física e exame de sementes com tegumento danificado foram submetidos à análise estatistica segundo esquema encontra do na tabela 1. 
Tabela 1. Esquema utilizado para a análise de variância dos dados obtidos para os testes análise de pureza física e exame de sementes com tegumento danificado

Causa de Variação

G.I.

Método de Beneficiamento (B)

Resíduo

6

21

Total

27

Os dados, expressos em porcentagem, foram submetidos à transformação angular " $\theta "=\operatorname{arc}$ sen $\sqrt{\frac{\partial}{0} / 100}$ sendo os arcos " $\theta$ " expressos em graus.

Para comparação entre médias utilizou-se o.tes te de Tukey ao nível de 5\% de probabilidade.

Os dados obtidos nos testes de germinação, envelhecimento acelerado e emergência em areia foram submetidos a análise estatística segundo esquema encontrado na tabela 2 .

Os dados expressos em porcentagem foram submetidos a transformação angular " $\theta$ " $=\operatorname{arc} \operatorname{sen} \sqrt{\frac{\partial}{6} / 100}$ sendo os arcos " $\theta$ " expressos em graus.

Para comparação entre médias utilizou-se o tes te de Tukey ao nível de 5\% de probabilidade. 
Tabela 2. Esquema utilizado para a anālise de variância dos dados obtidos para os testes de germinação, envelhecimento acelerado e emergência em areia.

Causa de Variação G.L.

Métodos de Beneficiamento (B) 6

Tratamento fungicida (F) 1

B X F 6

Resíduo 42

Total 55

Os dados obtidos no teste de emergência em cam po foi submetido a análise estatística segundo esquema encontrado na tabela 3 .

Tabela 3. Esquema utilizado para a análise de variância dos dados obtidos para o teste de emergência em campo.

Causa de Variação G.L.

Métodos de Beneficiamento (B) 6

Tratamento fungicida (F) 1

$\mathrm{B} \times \mathrm{F} \quad 6$

Blocos

3

Resíduo

39

Total 
Os dados expressos em porcentagem foram submetidos a transformação angular " $\theta "=\operatorname{arc} \operatorname{sen} \sqrt{\frac{\partial}{1100}}$ sendo os arcos " $\theta$ " expressos em graus. Para comparação entre médias utilizou-se 0 Teste de Tukey ao nível de 5\% de probabilidade. 


\section{RESULTADOS}

Os valores de $\mathrm{F}$ para efeito dos métodos de beneficiamento nos testes realizados nas respectivas épocas de anālise encontram-se na tabela 4.

Nesta tabela pode-se observar que com exceção do teste realizado para determinar a emergência em areia todos os outros foram significativos ao nível de 1\% de probabilidade com exceção do teste de germinação na 2 ạ época de aná lise que foi significativo ao nível de 5\% de probabilidade. A anālise da tabela reflete que existem diferenças entre os métodos de beneficiamento testados nas três épocas de análise.

Os valores de $F$ para efeito do tratamento fungicida nos testes realizados nas respectivas épocas de análise encontram-se na tabela 5 .

Observa-se nessa tabela que todos os testes fo ram significativos ao nível de 1\% de probabilidade, refletindo claramente que existem diferenças entre os tratamentos fungicidas testados nas três épocas de análise. 
Tabela 4. Valores de F para efeito dos métodos de beneficiamen to nos testes realizados nas respectivas épocas de análise $\left(E_{1}, 1\right.$ ạ época; $E_{2}, 2$ e época; $E_{3}$, 3ạ eṕoca; n.s., não significativo; *,significativo ao nível de $5 \%$ de probabilidade; **, significativo ao nível del\% de probabilidade).

\begin{tabular}{lccc}
\hline & \multicolumn{3}{c}{ Valores de $\mathrm{F}$} \\
\cline { 2 - 4 } Testes realizados & $\mathrm{E}_{1}$ & $\mathrm{E}_{2}$ & $\mathrm{E}_{3}$ \\
\hline Anālise de Pureza Física & $49,25 * *$ & - & - \\
Exame de Sementes com & $69,87 * *$ & - & - \\
tegumento danificado & $5,72 * *$ & $3,13 *$ & $8,64 * *$ \\
Teste de Germinação & $4,48 * *$ & $9,40 * *$ & $8,87 * *$ \\
Envelhecimento Acelerado & $1,53 \mathrm{~ns}$ & $1,64 \mathrm{~ns}$ & $1,46 \mathrm{~ns}$ \\
Emergência em Arẹia & $4,39 * *$ & $5,33 * *$ & $7,28 * *$ \\
Emergência em Campo & &
\end{tabular}

Tabela 5. Valores de F para efeito do tratamento fungicida. nos testes realizados nas respectivas épocas de análise $\left(E_{1}, 1\right.$ ạ época; $E_{2}, 2$ ạ época; $E_{3}$, 3ạ época; $n . s . n a ̃ o$ significativo; *, significativo ao nivel de 5\% de probabilidade; **, significativo ao nível de $1 \%$ de probabilidade).

Testes realizados

Valores de $\mathrm{F}$

\begin{tabular}{ccc}
\multicolumn{3}{c}{ Valores de $\mathrm{F}$} \\
\hline $\mathrm{E}_{1}$ & $\mathrm{E}_{2}$ & $\mathrm{E}_{3}$
\end{tabular}

Análise de Pureza Física

Exame de Sementes com

Tegumento danificado

Teste de Germinação

Envelhecimento Acelerado

$\begin{array}{rrr}192,60 * * & 564,67 * * & 17,68 * * \\ 278,18 * * & 176,13 * * & 28,14 * * \\ 75,87 * * & 62,66 * * & 38,21 * * \\ 782,75 * * & 581,68 * * & 1104,27 * *\end{array}$

Emergência em Areia

Emergência em Campo 
Os valores de $F$ para o efeito da interação métodos de beneficiamento $\mathrm{x}$ tratamento fungicida nos testes rea lizados nas respectivas épocas de análise encontram-se na tabela 6 .

Tabela 6. Valores de $F$ para efeito da interação métodos de be neficiamento $\mathrm{x}$ tratamento fungicida nos testes realizados nas respectivas épocas de análise $\left(E_{1}, \quad\right.$ lạ época; $E_{2}, 2$ a época; $E_{3}$, 3ạ época; n.s. não signifi cativo; *, significativo ao nível de $5 \%$ de probabili dade).

\begin{tabular}{lccc}
\hline & \multicolumn{3}{c}{ Valores de $\mathrm{F}$} \\
\cline { 2 - 4 } Testes realizados & $\mathrm{E}_{1}$ & $\mathrm{E}_{2}$ & $\mathrm{E}_{3}$ \\
\hline Análise de Pureza Física & - & - & - \\
$\begin{array}{l}\text { Exame de Sementes com } \\
\text { tegumento danificado }\end{array}$ & - & - & - \\
Teste de Germinação & $0,79 \mathrm{n} . \mathrm{s}$. & $1,43 \mathrm{n} . \mathrm{s}$. & $2,73 *$ \\
Envelhecimento Acelerado & $0,97 \mathrm{n} . \mathrm{s}$. & $1,26 \mathrm{n} . \mathrm{s}$. & $1,89 \mathrm{n} . \mathrm{s}$. \\
Emergência em Areia & $0,24 \mathrm{n} . \mathrm{s}$. & $1,1 \mathrm{n} . \mathrm{s}$. & $0,35 \mathrm{n} . \mathrm{s}$. \\
Emergência em Campo & $2,64 *$ & $1,46 \mathrm{n} . \mathrm{s}$. & $0,95 \mathrm{n} . \mathrm{s}$. \\
\hline
\end{tabular}

Observa-se nessa tabela 6 que com exceção dos testes realizados para determinar a porcentagem de germinação na 3ạ época de análise, e a emergência em campo, na lạ época de análise os quais foram significativos ao nível de $5 \%$ de 
probabilidade, os demais testes revelam não haver interação entre os métodos de beneficiamento e o tratamento fungicida, mostrando que o comportamento dos diferentes métodos de beneficiamento não depende do tratamento fungicida.

\subsection{Análise de Pureza Física}

A análise de variâncià dos dados referentes à porcentagem de pureza física revelou valores de F significativos ao nível de $1 \%$ de probabilidade, para o efeito de métodos de beneficiamento conforme tabela 4 .

Os valores médios originais e transformados re ferentes aos efeitos dos métodos de beneficiamento, bem como a diferença mínima significativa ao nível de 5\% de probabilidade e o coeficiente de variação são apresentados na tabela 7.

Observa-se nessa tabela 7 que dentro de todos os métodos de beneficiamento o tratamento 4 (três seleções eletrônicas apresentou maior porcentagem de pureza física que o tratamento 1 (testemunha), 6 (catação manual e eletrônica) e 7 (descarte), não diferindo significativamente dos outros tratamentos 2,3 e 5 os quais envolvem a catação das sementes. Os tratamentos $2,3,5$ e 6 não diferem entre si, mas apresentaram maior porcentagem de pureza física que o tratamento 7 (descarte). A testemunha, tratamento 1, 
Tabela 7. Análise de Pureza Física: médias obtidas para ofei to de beneficiamento (dados originais em $\%$ e dados transformados em arc sen $\sqrt{\mathrm{x} / 100}$ em graus), diferença mínima significativa ao nível de $5 \%$ de probabili dade e coeficiente de variação.

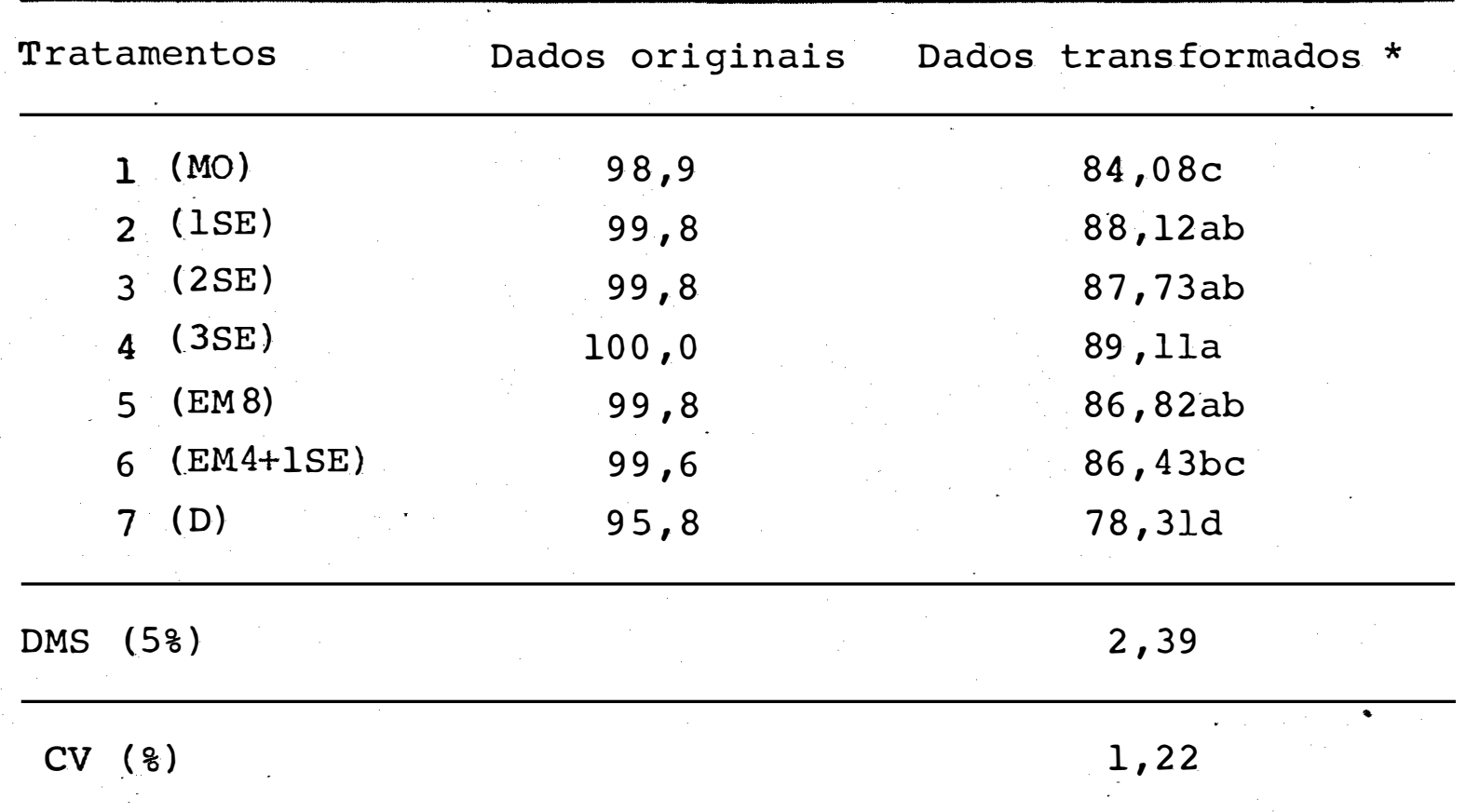

* Na mesma coluna, médias seguidas pela mesma letra não diferem significativamente entre si, pelo teste de Tukey ao nivel de $5 \%$ de probabilidade.

apresentou maior porcentagem de pureza física que o tratamento 7 (descarte), não diferindo estatisticamente do tratamento 6 (catação manual e eletrônica) e foi inferior, apresentando me nor porcentagem de pureza física, em comparação aos demaistra tamentos. O material descartado (tratamento 7) foi significa 
tivamente inferior a todos os demais tratamentos, apresentando a menor porcentagem de pureza física.

4.2. Exame de sementes com tegumento danificado

A análise de variância dos dados referentes ao exame de sementes com tegumento danificado revelou valores de F significativos ao nível de $1 \%$ de probabilidade, para 0 efei to de métodos de beneficiamento conforme tabela 4 .

Os valores médios originais e transformados re lativos aos efeitos dos métodos de beneficiamento, bem como a diferença mínima significativa ao nível de 5\% de probabilidade e o coeficiente de variação são apresentados na tabela 8.

Observa-se nessa tabela 8 que o tratamento 7 (descarte) apresentou maior porcentagem de sementes com o tegumento danificado que os demais tratamentos. o tratamento 1 (testemunha) apresentou menor porcentagem de sementes com 0 tegumento danificado em comparação com o descarte e foi estatis ticamente semelhante ao tratamento 6 (catação manual seguida de seleção eletrônica) e revelou maior porcentagem de sementes com tegumento danificado que os tratamentos $2,3,4$ e 5 todos envolvendo a catação das sementes. O tratamento 6 não diferiu significativamente dos tratamentos 2,3 e 5 os quais envolvem a catação das sementes, mas apresentou uma maior por 
centagem de sementes com tegumento danificado quando comparado com o tratamento 4-(três seleções eletrônicas).

Tabela 8. Exame de Sementes com Tegumento Danificado: médias obtidas para efeito do beneficiamento (dados originais em $\%$ e dados transformados em arc sen $\sqrt{x} 7100$ em graus) diferença mínima significativa ao nível de 5\% de probabilidade e coeficiente de variação.

\begin{tabular}{|c|c|c|}
\hline Tratamentos & Dados originais & Dadds transformados* \\
\hline 1 (MO) & 16,1 & $23,64 c$ \\
\hline 2 (ISE) & 12,1 & $20,35 a b$ \\
\hline 3 (2SE) & 10,7 & $19,07 \mathrm{ab}$ \\
\hline 4 (3SE) & 10,0 & $18,48 a$ \\
\hline 5 (EM 8$)$ & 10,6 & $18,94 \mathrm{ab}$ \\
\hline $6(\mathrm{EM} 4+1 \mathrm{SE})$ & 13,8 & $21,81 \mathrm{bc}$ \\
\hline 7 (D) & 30,5 & $33,51 d$ \\
\hline DMS $(5 \%)$ & & 2,90 \\
\hline $\mathrm{CV}\left(\frac{\circ}{)}\right)$ & & 5,69 \\
\hline
\end{tabular}

* Na mesma coluna, médias seguidas pela mesma letra não diferem significativamente entre si, pelo teste de Tukey ao nível de $5 \%$ de probabilidade. 


\subsection{Teste de germinação}

A análise de variância dos dados referentes ao teste de germinação revelou valores de $\mathrm{F}$ significativos ao ní vel de $1 \%$ de probabilidade para o efeito de métodos de beneficiamento para lạ e 3ạ épocas de análise e 5\% de probabilidą de para a 2 é época de análise conforme tabela 4.

Observa-se na tabela 9 , para efeito de métodos de beneficiamento, que os tratamentos $2,3,4,5$ e 6 os quais envolvem a catação de sementes não diferiram significativamen te do tratamento 1 (testemunha) mas todos foram significativa mente superiores apresentando maior porcentagem de germinação que $\circ$ tratamento $7 \circ$ qual representa as sementes descartadas pela catação eletrônica para a lạ época de análise. o exame da tabela 9 revela que cabe semelhante interpretação para a 3ạ época de análise. Na 2ạ época de anălise os tratamentosl, $2,3,4,5$ e 6 foram estatisticamente semelhantes entre si. Os tratamentos 1, 2, 5 e 6 não diferiram estatisticamente do tratamento 7 (descarte). Os tratamentos 3 e 4 respectivamente, duas catações eletrônicas e três seleções eletrônicas foram estatisticamente superiores ao tratamento 7 (descarte).

Na tabela 5, observa-se que os valores de $F$ são significativos ao nível de $1 \%$ de probabilidade nas três épocas de análise para o efeito de tratamento fungicida.

A observação da tabela 10, para o efeito do tratamento fungicida, em todas as épocas de análise as semen- 
tes tratadas foram significativamente superiores as sementes não tratadas.

Tabela 9. Teste de Germinaçãö: médias obtidas para o efeito de métodos de beneficiamento (dados originais em $\%$ e dados transformados em arc sen $\sqrt{\mathrm{x} / 100}$ em graus), diferença mínima significativa ao nível de $5 \%$ de probabilidade e coeficiente de variação nas três épo cas de análise $\left(E_{1}, 1\right.$ ạ época; $E_{2}, 2^{a}$. época; $E_{3}$, 3ạ época).

\begin{tabular}{|c|c|c|c|c|c|c|}
\hline \multirow{2}{*}{ Tratamentos } & \multicolumn{3}{|c|}{ Dados originais } & \multicolumn{3}{|c|}{ Dados transformados* } \\
\hline & $\mathrm{E}_{1}$ & $\mathrm{E}_{2}$ & $E_{3}$ & $E_{1}$ & $\mathrm{E}_{2}$ & $\mathrm{E}_{3}$ \\
\hline $1 \quad(M O)$ & 87 & 74 & 47 & $69,93 a$ & $60,10 \mathrm{ab}$ & 42,68 \\
\hline 2 (ISE) & 87 & 73 & 45 & $70,31 a$ & $59,62 a b$ & 41,95 \\
\hline 3 (2SE) & 88 & 78 & 50 & $72,32 a$ & $62,74 a$ & 45,00 \\
\hline 4 (3SE) & 90 & 77 & 47 & $72,95 a$ & $62,70 a$ & 42,97 \\
\hline 5 (EM8) & 88 & 75 & 45 & $70,59 a$ & $60,57 a b$ & 42,16 \\
\hline $6 \quad(E M 4+1 S E)$ & E) 90 & 74 & 45 & $72,46 a$ & $56,92 \mathrm{ab}$ & 42,03 \\
\hline 7 (D) & 77 & 69 & 29 & $61,96 b$ & $57,23 b$ & 32,10 \\
\hline DMS $(5 \%)$ & & & & 6,90 & 4,71 & 6,21 \\
\hline $\mathrm{CV}(\%)$ & & & & 6,36 & 5,04 & 9,73 \\
\hline
\end{tabular}

* Na mesma coluna, médias seguidas pela mesma letra não diferem significativamente entre si, pelo teste de Tukey ao nível de $5 \%$ de probabilidade. 
Tabela 10. Teste de Germinação: médias obtidas para o efeito do tratamento fungicida (dados originais em $\%$ e da dos transformados em arc sen $\sqrt{\mathrm{x} / 100}$ em graus), diferença mínima significativa ao nível de $5 \%$ de pro babilidade e coeficiente de variação nas três épocas de análise $\left(E_{1}, 1\right.$ a época; $E_{2}$, 2a época; $E_{3}$, 3ạ época).

\begin{tabular}{|c|c|c|c|c|c|c|}
\hline \multirow{2}{*}{ Tratamentos } & \multicolumn{3}{|c|}{ Dados originais } & \multicolumn{3}{|c|}{ insformados* } \\
\hline & $E_{1}$ & $\mathrm{E}_{2}$ & $\mathrm{E}_{3}$ & $\mathrm{E}_{1}$ & $E_{2}$ & $\mathrm{E}_{3}$ \\
\hline Tratadas & 96 & 88 & 48 & $78,34 a$ & $70,07 a$ & 43,53 \\
\hline Não tratadas & 77 & 60 & 40 & $61,81 b$ & $50,75 b$ & 39,01 \\
\hline DMS $(5 \circ)$ & & & & 2,40 & 1,64 & 2,16 \\
\hline CV $\left(\frac{8}{8}\right)$ & & & & 6,36 & 5,04 & 9,73 \\
\hline
\end{tabular}

* Na mesma coluna médias seguidas pela mesma letra não diferem significativamente entre si, pelo teste de Tukey ao nivel de $5 \%$ de probabilidade.

Na tabela 6 , observa-se que os valores de $F$ não foram significativos na lạ e 2ạ épocas de análise e na 3ạ época de análise foram significativos ao nível de $5 \%$ de probabilidade para efeito da interação tratamento fungicida dentro de métodos de beneficiamento.

o exame da tabela 11 , para efeito da interação 
tratamento fungicida dentro de métodos de beneficiamento na 3ạ época de análise revela que as sementes tratadas não diferiram das não tratadas dentro dos métodos de beneficiamento 1, $2,3,5$ e 6 . Nos métodos de beneficiamento 4 (três seleções eletrônicas) e 7 (descarte) as sementes tratadas foram significativamente superiores as sementes não tratadas.

Tabela 11. Teste de Germinação: médias obtidas para o efeito da interação tratamento fungicida dentro de métodos de beneficiamento (dados originais em $\%$ e dados transformados em arc sen $\sqrt{\mathrm{x} / 100}$ em graus), diferença mínima significativa ao nível de 5\% de pro babilidade e coeficiente de variação na $3 a ̣$ época de anālise

\begin{tabular}{|c|c|c|c|c|c|}
\hline \multirow{3}{*}{ Tratamentos } & \multicolumn{5}{|c|}{ Tratamento fungicida } \\
\hline & \multicolumn{2}{|c|}{ Dados originais } & \multicolumn{3}{|c|}{ Dados transformados* } \\
\hline & Tratadas & Não tratadas & Tratadas & Não & tratacas \\
\hline $1(\mathrm{MO})$ & 51 & 42 & $45,29 a$ & & $40,07 a$ \\
\hline 2 (ISE) & 49 & 40 & $44,45 a$ & & $39,35 a$ \\
\hline $3(2 S E)$ & 52 & 48 & $46,29 a$ & & $43,70 a$ \\
\hline 4 (3SE) & 52 & 41 & $46,02 a$ & & $39,92 b$ \\
\hline 5 (EM8) & 49 & 41 & $44,42 a$ & & $39,90 a$ \\
\hline $6(\mathrm{EM} 4+1 \mathrm{SE})$ & 42 & 48 & $43,99 a$ & & $40,08 a$ \\
\hline 7 (D) & 38 & 20 & $38,04 a$ & & $26,16 b$ \\
\hline DMS $(5 \%)$ & & & \multicolumn{3}{|c|}{5,73} \\
\hline $\mathrm{CV}$ (응 & & & \multicolumn{3}{|c|}{9,73} \\
\hline
\end{tabular}

* Na mesma linha, médias seguidas pela mesma letra não diferem entre si, pelo teste de Tukey ao nível de 5\% de probabi lidade. 
Observa-se na tabela 12, para efeito da interação métodos de beneficiamento dentro de tratamento fungicida na 3ạ época de análise que todos os métodos de beneficiamento não diferiram estatisticamente entre si quando as semen tes foram tratadas. Quando as sementes não foram tratadas o tratamento 7 (descarte) foi significativamente inferior aos de mais tratamentos os quais foram estatisticamente semelhantes entre si.

\subsection{Envelhecimento acelerado}

A análise de variância dos dados referentes ao teste de envelhecimento acelerado revelou valores de F significativos ao nível de $1 \%$ de probabilidade, para efeito ' dos métodos de beneficiamento, conforme tabela 4 e para efeito do tratamento fungicida conforme tabela 5 nas três épocas de anā lise.

O exame da tabela 13, para efeito dos métodos de beneficiamento, revela que os tratamentos 1 (testemunha), $2,3,4,5$ e 6 os quais envolvem a catação das sementes não diferiram significativamente entre si e foram estatisticamente superiores ao tratamento 7 (descarte) para as três épocas de análise.

Observa-se na tabela 14, para efeito do tratamento fungicida, que as sementes tratadas foram significativa 
mente superiores às sementes não tratadas nas três épocas de anālise.

Na tabela 6 , observa-se que os valores de $F$ não foram significativos para o efeito da interação métodos de beneficiamento $x$ tratamento fungicida nas três épocas de anālise.

Tabela 12. Teste de Germinação: médias obtidas para o efeito da interação métodos de beneficiamento dentro de tratamento fungicida (dados originais em $\%$ e dados transformados em arc sen $\sqrt{\mathrm{x} / 100}$ em graus), diferen ça mínima significativa ao nivel de $5 \%$ de probabilidade e coeficiente de variação na 3ạ época de análise.

\begin{tabular}{|c|c|c|c|c|}
\hline \multirow{3}{*}{ Tratamentos } & \multicolumn{4}{|c|}{ Tratamento fungicida } \\
\hline & \multicolumn{2}{|c|}{ Dados originais } & \multicolumn{2}{|c|}{ Dados transformados * } \\
\hline & Tratadas & Não tratadas & Tratadas & Não tratadas \\
\hline 1 (MO) & 51 & 42 & $45,29 a$ & $40,07 a$ \\
\hline 2 (ISE) & 49 & 40 & $44,55 a$ & $39,35 a$ \\
\hline 3 (2SE) & 52 & 48 & $46,29 a$ & $43,70 a$ \\
\hline 4 (3SE) & 52 & 41 & $46,02 a$ & $39,92 \mathrm{a}$ \\
\hline 5 (EM8) & 49 & 41 & $44,42 a$ & $39,90 a$ \\
\hline 6 (EM4+1SE) & 42 & 48 & $43,99 a$ & $43,99 a$ \\
\hline 7 (D) & 38 & 20 & $38,04 a$ & $26,16 b$ \\
\hline DMS $(5 \%)$ & & & \multicolumn{2}{|c|}{8,79} \\
\hline $\mathrm{CV}(\%)$ & & & \multicolumn{2}{|c|}{9,73} \\
\hline
\end{tabular}

* Na mesma coluna, médias seguidas pela mesma letra não diferem entre si, pelo teste de Tukey ao nível de 5\% de probabi lidade. 
Tabela 13. Envelhecimento Acelerado: médias obtidas para o efeito de métodos de beneficiamento (dados originais em $\frac{e}{e}$ dados transformados em arc sen $\sqrt{\mathrm{x} / 100}$ em graus), diferença mínima significativa ao nivel de $5 \%$ de probabilidade e coeficientes de variação, nas três épocas de análise $\left(E_{1}, 1\right.$ ạ época; $E_{2}$, 2ạ época: $\mathrm{E}_{3 .}$, 3ạ época).

\begin{tabular}{|c|c|c|c|c|c|c|}
\hline \multirow{2}{*}{ Tratamentos } & \multicolumn{3}{|c|}{ Dados originais } & \multicolumn{3}{|c|}{ Dados transformados * } \\
\hline & $E_{1}$ & $\mathrm{E}_{2}$ & $\vec{E}_{3}$ & $E_{1}$ & $\mathrm{E}_{2}$ & $E_{3}$ \\
\hline 1 (MO) & 73 & 51 & 19 & $59,45 a$ & $46,65 a$ & $25,49 a$ \\
\hline 2 (ISE) & 75 & 57 & 19 & $60,44 \mathrm{a}$ & $48,72 a$ & $24,99 a$ \\
\hline 3 (2SE) & 77 & 54 & 21 & $61,92 \mathrm{a}$ & $46,96 a$ & $26,42 a$ \\
\hline $4 \quad(3 \mathrm{SE})$ & 77 & 54 & 18 & $61,61 a$ & $47,17 a$ & $24,80 a$ \\
\hline 5 (EM8) & 76 & 54 & 20 & $60,89 a$ & $48,09 a$ & $26,09 a$ \\
\hline 6 (EMA+1SE) & 74 & 54 & 17 & $60.71 \mathrm{a}$ & $47,31 a$ & $23,87 a$ \\
\hline 7 (D) & 63 & 41 & 10 & $53,30 b$ & $39,68 b$ & $17,82 \mathrm{~b}$ \\
\hline DMS $(5 \%)$ & & & & 6,11 & 4,34 & 4,32 \\
\hline $\mathrm{CV}(\%)$ & & & & 6,61 & 6,07 & 11,54 \\
\hline
\end{tabular}

* Na mesma coluna, médias seguidas pela mesma letra não diferem entre si, pelo teste de Tukey ao nível de $5 \%$ de proba bilidade. 
Tabela 14. Envelhecimento Acelerado: médias obtidas para o efeito do tratamento fungicida (dados originais em: o e dados transformados em arc sen $\sqrt{\mathrm{x} / 100}$ em graus) diferença mínima significativa ao nivel de $5 \%$ de probabilidade e coeficiente de variação nas três épocas de análise $\left(E_{1}, 1\right.$ à época; $E_{2}, 2$ a época; $E_{3}$, 3a época).

\begin{tabular}{|c|c|c|c|c|c|c|}
\hline \multirow{2}{*}{ Tratamento } & \multicolumn{3}{|c|}{ Dados originais } & \multicolumn{3}{|c|}{ Dados transformados * } \\
\hline & $E_{1}$ & $\mathrm{E}_{2}$ & $\mathrm{E}_{3}$ & $\mathrm{E}_{1}$ & $\mathrm{E}_{2}$ & $\mathrm{E}_{3}$ \\
\hline Tratadas & 86 & 60 & 20 & $65,57 \mathrm{a}$ & $51,20 a$ & $26,19 a$ \\
\hline Não tratadas & 60 & 43 & 15 & $50,96 b$ & $41,25 b$ & $22,23 b$ \\
\hline DMS (5\%) & & & & 2,13 & 1,51 & 1,50 \\
\hline $\mathrm{CV}\left(\frac{\%}{6}\right)$ & & & & 6,61 & 6,07 & 11,54 \\
\hline
\end{tabular}

* Na mesma coluna, médias seguidas pela mesma letra não diferem entre si, pelo teste de Tukey, ao nível de 5\% de probabilidade.

\subsection{Emergência em Areia}

A análise de variância dos dados referentes a porcentagem de emergência em areia revelou valores de $F$ não significativos para o efeito de métodos de beneficiamento e para a interação métodos de beneficiamento $x$ tratamento fun- 
gicida nas três épocas de anălise conforme tabelas 4 e 6 respectivamente. Na tabela-5 observa-se que os valores de $\mathrm{F}$ foram significativos ao nível de 1\% de probabilidade para 0 efeito de tratamento fungicida nas três épocas de análise.

Examinando-se a tabela 15 para efeito do trata mento fungicida, verifica-se que as sementes tratadas foram significativamente superiores as sementes não tratadas em todas as épocas de análise.

\subsection{Emergência em campo .}

A análise de variância dos dados referentes ao teste de emergência em campo revelou valores de $F$ significa tivos ao nível de $1 \%$ de probabilidade, para efeito de métódos de beneficiamento, conforme tabela 4 e para efeito de tratamento fungicida conforma tabela 5, nas três épocas de análise.

Examinando-se a tabela 16 para efeito de métodos de beneficiamento para a lạ época de análise verifica-se que os tratamentos $1,2,3,4,5$ e 6 não diferiram estatisticamente entre si e que os tratamentos 1 (testemunha), 2 (uma seleção eletrônica) e 5 (catação manual) foram superiores ao tratamento 7 (descarte). Por sua vez o tratamento 7 não diferiu estatisticamente dos tratamentos 3 (duas seleções eletrônicas), 4 (três seleções eletrônicas) e 6 (catação manual 
Tabela 15. Emergência em Areia: médias obtidas para o efeito de tratamento fungicida (dados originais em $\%$ e da dos transformados em arc sen $\sqrt{x / 100}$ em graus), diferença mínima significativa ao nível de 5\% de pro babilidade e coeficiente de variação nas três épocas de análise $\left(E_{1}, 1\right.$ ạ época; $E_{2}$, 2ạ época; $E_{3}$, 3ạ época) :

\begin{tabular}{|c|c|c|c|c|c|c|}
\hline \multirow{2}{*}{ Tratamentos } & \multicolumn{3}{|c|}{ Dados originais } & \multirow[t]{2}{*}{ Dados } & \multicolumn{2}{|c|}{ transformados * } \\
\hline & $E_{1}$ & $\mathrm{E}_{2}$ & $\mathrm{E}_{3}$ & & $\mathrm{E}_{2}$ & $\mathrm{E}_{3}$ \\
\hline Tratadas & 80 & 87 & 51 & $63,69 a$ & $68,95 a$ & $45,50 a$ \\
\hline Não tratadas & 57 & 70 & 34 & $48,98 b$ & $57,10 b$ & $34,96 \mathrm{~b}$ \\
\hline $\operatorname{DMS} \quad(5 \%)$ & & & & 3,04 & $3 ., 02$ & 3,44 \\
\hline $\mathrm{CV}\left(\frac{\circ}{0}\right)$ & & & & 11,21 & 8,89 & 15,85 \\
\hline
\end{tabular}

* Na mesma coluna, médias seguidas pela mesma letra não diferem entre si pelo teste de Tukey ao nível de 5\% de probabilidade.

e seleção eletrônical. Para 2ạ e $3^{a}$. épocas de análise verifi camos que os tratamentos $1,2,3,4,5$ e 6 foram estatisticamente semelhantes entre si e superiores ao tratamento 7 (descarte). O tratamento 7 (descarte) apresentou a menor porcen tagem em todas as épocas. 
Tabela 16. Emergência em Campo: médias obtidas para o efeito de métodos de beneficiamento (dados originais em \% e dados transformados em arc sen $\sqrt{x / 100}$ em graus), diferença mínima significativa ao nível de 5\% de probabilidade e coeficiente de variação nas três épocas de anālise $\left(E_{1}, 1\right.$ ạ época; $E_{2}, 2^{a}$ época, $E_{3}$, 3ạ época).

\begin{tabular}{|c|c|c|c|c|c|c|}
\hline \multirow{2}{*}{ Tratamentos } & \multirow{2}{*}{$\frac{\text { Dados }}{E_{1}}$} & \multicolumn{2}{|c|}{ originais } & \multicolumn{2}{|c|}{ Dados transfo } & $\operatorname{ados}$ * \\
\hline & & $\mathrm{E}_{2}$ & $E_{3}$ & $E_{1}$ & $\mathrm{E}_{2}$ & $E_{3}$ \\
\hline I. (MO) & 63 & 65 & 52 & 52,39 & $53,64 a$ & $46,28 a$ \\
\hline 2 (ISE) & 62 & 65 & 51 & 52,55 & $53,76 a$ & $45,57 a$ \\
\hline 3 (2SE) & 60 & 65 & 54 & 51,17 & $54,21 a$ & $46,22 a$ \\
\hline 4 (3SE) & 56 & 64 & 53 & 48,85 & $53,36 a$ & $46,70 a$ \\
\hline 5 (EM8) & 62 & 65 & 54 & 52,21 & $54,11 a$ & $47,15 a$ \\
\hline $6(E M 4+1 S E)$ & 61 & 66 & 49 & 51,09 & $54,69 a$ & $43,82 a$ \\
\hline 7 (D) & 55 & 57 & 40 & 47,59 & $48,78 b$ & $38,27 \mathrm{~b}$ \\
\hline DMS (5\%) & & & & 4,00 & 3,82 & 5,19 \\
\hline $\mathrm{CV}(\%)$ & & & & 5,07 & 4,62 & 7,43 \\
\hline
\end{tabular}

* Na mesmá coluna, médias seguidas pela mesma letra não diferem significativamente entre si, pelo teste de Tukey ao nível de 5\% de probabilidade.

Observa-se na tabela 17, para efeito do tratamento fungicida, que as sementes tratadas foram significativa mente superiores as sementes não tratadas nas três épocas de anālise. 
Tabela 17. Emergência em Campo: médias obtidas para o efeito de tratamento fungicida (dados originais em \% e da dos transformados em arc sen $\sqrt{\mathrm{x} / 100}$ em graus), diferença mínima significativa ao nível de 5\% de pro babilidade e coeficiente de variação nas três épocas de análise $\left(E_{1}, 1\right.$ ạ época; $E_{2}, 2$ a época; $E_{3}$ ' 3ä. época).

\begin{tabular}{|c|c|c|c|c|c|c|}
\hline \multirow{2}{*}{ Tratamentos } & \multicolumn{3}{|c|}{ Dados originais } & \multicolumn{3}{|c|}{ Dados transformados * } \\
\hline & $E_{1}$ & $\mathrm{E}_{2}$ & $\mathrm{E}_{3}$ & $E_{I}$ & $E_{2}$ & $\mathrm{E}_{3}$ \\
\hline Tratadas & 76 & 77 & 74 & 60,47 & $65,15 a$ & $59,85 a$ \\
\hline Não tratadas & 43 & 51 & 26 & 41,20 & $45,30 b$ & $30,15 b$ \\
\hline $\operatorname{DMS} \quad(5 \%)$ & & & & 1,39 & 1,33 & 1,80 \\
\hline $\mathrm{CV}$ (\%) & & & & 5,07 & 4,62 & 7,43 \\
\hline
\end{tabular}

* Na mesma coluna, médias seguidas pela mesma letra não diferem significativamente entre si pelo teste de rukey ao nível de 5\% de probabilidade.

Na tabela 6 observa-se que os valores de $F$ foram significativos ao nível de 5\% de probabilidade para o efeito da interação métodos de beneficiamento $\mathrm{x}$ tratamento fun gicida na lạ época de análise; entretanto na $2 \stackrel{a}{\text { e }} 3^{a}$ é épocas de análise os valores de $F$ não foram significativos.

O exame da tabela 18, para efeito da interação 
tratamento fungicida dentro de métodos de beneficiamento, na 1. época de análise do teste de emergência em campo, revela que as sementes tratadas foram significativamente superiores as sementes não tratadas dentro de todos os métodos de beneficiamento.

Tabela 18. Emergência em Campo: médias obtidas para o efeito da interação tratamento fungicida dentro de métodos de beneficiamento (dados originais em $\%$ dados transformados em arc sen $\sqrt{\mathrm{x} / 100}$ em graus), diferença mínima significativa ao nível de 5\% de pro babilidade e coeficiente de variação na lạ época de análise.

\begin{tabular}{|c|c|c|c|c|}
\hline \multirow{3}{*}{ Tratamentos } & \multicolumn{4}{|c|}{ Tratamento fungicida } \\
\hline & \multicolumn{2}{|c|}{ Dados originais } & \multicolumn{2}{|c|}{ Dados transformados * } \\
\hline & Tratadas & Não tratadas & Tratadas & Não tratadas \\
\hline$I(M O)$ & 76 & 49 & $60,50 a$ & $44,28 b$ \\
\hline 2 (ISE) & 77 & 47 & $61,64 a$ & $43,46 b$ \\
\hline $3 \quad(2 S E)$ & 76 & 44 & $60,59 a$ & $41,76 b$ \\
\hline $4 \quad(3 S E)$ & 76 & 36 & $60,80 a$ & $36,91 b$ \\
\hline $5 \quad(E M)$ & 77 & 47 & $61,00 \mathrm{a}$ & $43,42 b$ \\
\hline $6 \quad(E M 4+1 S E)$ & 75 & 46 & $56,70 a$ & $42,48 b$ \\
\hline 7 (D) & 74 & 35 & $59,07 a$ & $36,11 b$ \\
\hline $\operatorname{DMS} \quad(5 \%)$ & & & & .68 \\
\hline $\mathrm{CV} \quad(\%)$ & & & &, 07 \\
\hline
\end{tabular}

* Na mesma linha, médias seguidas pela mesma letra não diferem significativamente entre si pelo teste de Tukey ao ní vel de 5\% de probabilidade. 
Observa-se na tabela 19, para efeito da intera çao métodos de beneficiamento dentro de tratamento fungicida na lạ epoca de análise do teste de emergência em campo, que todos os métodos de beneficiamento não diferiram estatisticamente entre si, quando as sementes foram tratadas. Quando as sementes não foram tratadas os tratamentos 1 (testemunha), 2 (uma seleção eletrônica) e 5 (catação manual) foram estatistí camente semelhantes entre si e superiores aos tratamentos 4 (três seleções eletrônicas) e 7 (descarte). 0 tratamento 6 (catação manual e eletrônica) foi estatisticamente semelhante aos tratamentos 1, 2, 3, 4 e 5 e superior ao tratamento 7 (descarte). O tratamento 4 (três seleções eletrônicas) foi semelhante aos tratamentos 3, 6 e 7 .

\subsection{Exame de Sanidade das Sementes}

As médias obtidas com os dados do exame de sanidade de sementes são apresentadas individualmente para as ocorrências de Penicillium spp., Aspergillus spp. e Rhizopus sp. e sao encontrados na tabela 20.

Na tabela 20 consta as ocorrências apenas dos fungos Penicillium spp., Aspergillus spp e Rhizophus sp." pois foram os mais frequentes, não obstante tenha ocorrido o fungo cladosporium spp. e bactérias, mas estes últimos em muito bai xa frequência e por esta razão não constam na tabela. Cabe, 
Tabela 19. Emergência em Campo: médias obtidas para o efeito da interação métodos de beneficiamento dentro de tratamento fungicida (dados originais em $\%$ e daảos transformados em arc sen $\sqrt{\mathrm{x} / 100}$ em graus), diferença mínima significativa ao nível de 5\% de proba bilidade e coeficiente de variação na lạ épóca de análise.

\begin{tabular}{|c|c|c|c|c|}
\hline \multirow{3}{*}{ Tratamentos } & \multicolumn{4}{|c|}{ Tratamento fungicida } \\
\hline & \multicolumn{2}{|c|}{ Dados originais } & \multicolumn{2}{|c|}{ Dados transformados * } \\
\hline & Tratadas & Não tratadas & Tratadas & Não tratadas \\
\hline 1 (MO) & 76 & 49 & $60,50 a$ & $44,28 a$ \\
\hline 2 (ISE) & 77. & 47 & $61,64 a$ & $43,46 a$ \\
\hline $3 \quad(2 S E)$ & 76 & 44 & $60,59 a$ & $41,76 \mathrm{abc}$ \\
\hline $4 \quad$ (3SE) & 76 & 36 & $60,80 a$ & $36,9 \mathrm{lbc}$ \\
\hline $5 \quad(E M)$ & 77 & 47 & $61,00 a$ & $43,42 \mathrm{a}$ \\
\hline 6 (EM4+1SE) & 75 & 46 & $59,70 a$ & $42,48 a b$ \\
\hline 7 (D) & 74 & 35 & $59,07 a$ & $36,11_{C}$ \\
\hline DMS $(5 \%)$ & & & & 66 \\
\hline CV (\%) & & & & 07 \\
\hline
\end{tabular}

* Na mesma coluna, médias seguidas pela mesma letra não diferem significativamente entre si pelo teste de Tukey ao ní vel de 5\% de probabilidade. 
também, ressaltar que o exame de sanidade de sementes foi con duzido apenas na 3ạ época de análise.

Tabela 20. Exame de Sanidade das Sementes: ocorrência média de Penicillium spp, Aspergillus spp e Rhizopus sp. (Dados originais em $\%$ ).

\begin{tabular}{|c|c|c|c|c|c|c|}
\hline \multirow{3}{*}{$\begin{array}{l}\text { Trata- } \\
\text { mentos }\end{array}$} & \multicolumn{6}{|c|}{ Patógenos - Dados originais } \\
\hline & \multicolumn{2}{|c|}{ Penicillium spp. } & \multicolumn{2}{|c|}{ Aspergillus spp. } & \multicolumn{2}{|c|}{ Rhizopus sp. } \\
\hline & $\begin{array}{c}\text { sem } \\
\text { assepsia }\end{array}$ & $\begin{array}{c}\text { com } \\
\text { assepsia }\end{array}$ & $\begin{array}{c}\text { sem } \\
\text { assepsia }\end{array}$ & $\begin{array}{c}\text { com } \\
\text { assepsia }\end{array}$ & $\begin{array}{c}\text { sem } \\
\text { assepsia }\end{array}$ & $\begin{array}{c}\text { Com } \\
\text { assepsia }\end{array}$ \\
\hline 1 (MO) & 42,5 & 3,0 & 80,0 & 15,0 & 25,5 & 15,5 \\
\hline 2 (ISE) & 47,0 & 1,5 & 88,5 & 19,5 & 18,5 & 11,0 \\
\hline 3 (2SE) & 49,5 & 2,0 & 86,5 & 25,5 & 18,0 & 4,0 \\
\hline $4(3 \mathrm{SE})$ & 39,5 & 1,0 & 65,5 & 20,0 & 10,5 & 8,5 \\
\hline 5 (EM8) & 49,5 & 3,0 & 84,0 & 25,5 & 18,0 & 18,5 \\
\hline 6 (EM4+ISE) & 63,5 & 2,5 & 79,5 & 13,0 & 24,5 & 14,0 \\
\hline $7(\mathrm{D})$ & 47,0 & 0,0 & 82,0 & 29,5 & 29,0 & 20,0 \\
\hline$I(T)$ & 0,0 & & 0,0 & & 0,0 & \\
\hline $2(T)$ & 0,0 & & 0,0 & & 0,0 & \\
\hline $3(T)$ & 0,0 & & 1,0 & & 0,5 & \\
\hline $4(T)$ & 0,0 & & 1,0 & & 0,0 & \\
\hline $5(T)$ & 0,0 & & 0,5 & & 0,0 & \\
\hline $6(T)$ & 0,0 & & 1,5 & & 0,0 & \\
\hline $7(T)$ & 0,0 & & 2,5 & & 0,5 & \\
\hline
\end{tabular}

Observa-se na tabela 20 para a ocorrência de Penicillium spp que as sementes não tratadas e sem assepsia superficial apresentam alta porcentagem de infecção e que os 
tratamentos 6 (catação manual e eletrônica, sem assepsia) des tacou-se com a mais alta porcentagem de infecção $(63,5 \%)$ das sementes e o tratamento 4 (três seleções eletrônicas, sem assepsia) com a mais baixa $(39,5 \%)$. Quando foi realizada a assepsia superficial das sementes com hipoclorito de sódio, ocor reu drástica redução da porcentagem de sementes afetadas por Penicillium spp., destacando-se os tratamentos 1 (testemunha), 5 (catação manual) e 6 (catação manual e eletrônica) com as maiores porcentagens de infecção $(3,0 \%, 3,0 \%$ e $2,5 \%$ ) das sementes. As sementes que receberam tratamento fungicida não foram afetadas pelo fungo Penicillium spp. independente do mê todo de beneficiamento a que foram submetidas.

Examinando-se a tabela 20 para a ocorrência de Aspergillus spp. observa-se que as sementes não tratadas e sem assepsia superficial apresentaram elevados niveis de infecção das sementes com média de $80 \%$ das sementes infeccionadas; observa-se ainda que o tratamento 4 (três seleções eletrôni cas) apresentou a menor porcentagem de senentes infeccionadas $(65,5 \%)$ por Aspergillus spp dentre as sementes que não receberam tratamento fungicida. Quando a assepsia superficialdas sementes foi realizada, ocorreu acentuada redução no nível de ocorrência de Aspergillus spp, para uma média de $21 \%$, sendo que o tratamento 7 (descarte com assepsia) apresentou o maior nível de infecção das sementes por Aspergillus spp, 29,5\%. Por outro lado, o nível de ocorrência de Aspergillus spp. foi muito baixo, quando as sementes receberam tratamento fungici- 
da; neste caso destaca-se o tratamento 7 (descarte) o qual apresentou o maior nível de infecção"por Aspergillus spp.

Com relação a ocorrência do fungo Rhizopus sp. nas sementes, observa-se na tabela 20 que as sementes não tratadas e sem assepsia superficial apresentaram os maiores níveis de infecção, destacando o tratamento 7 (descarte) com o maior nível de infecção $29,0 \%$ e o tratamento 4 (três seleções eletrônicas) com o menor nível de infecção 10,5\%. Entretanto, redução do nível de ocorrência de Rhizopus sp. com a assepsia superficial das sementes foi pouco acentuada e o tratamento 7 (descarte com assepsia) continuou apresentando a maior taxa de infecção de Rhizopus sp. nas sementes. As sementes tratadas com fungicida apresentaram $0,5 \%$ de sementes com incidência de R.hizopus sp para os tratamentos 3 e 7 e zero 음 ra os demais tratamentos. 


\section{DISCUSSÃO}

A análise de variância dos dados e a interpretação dos resultados contidos na tabela 4, revelam que existem diferenças entre os métodos de beneficiamentos testados e que os elevados valores de $F$ contidos na tabela 5 demonstram a elevada probabilidade da diferença entre os tratamentos fun gicidas. Pelas tabelas referentes a germinação, envelhecimento acelerado, emergência em areiae campo verifica-se que os testes escolhidos foram adequados para avaliar a qualidade das sementes porque os resultados obtidos foram uniformes.

Verifica-se também, pela tabela 6 que o compor tamento dos métodos de beneficiamento não dependém do tratamento fungicida realizado pois com exceção do teste de germinação realizado na 3 ạ época e o teste de emergência em campo na lạ época de análise, todos os demais testes mostraram valores de $F$ não significativos para a interação.

Os valores da porcentagem de pureza física encontrados na tabela 7 revelam que o material original possuia 
elevada pureza física $(98,9 \%)$, pois as sementes após o descas. camento haviam passado por uma máquina de limpeza e classificação e, em seguida, pela mesa gravitacional, onde foi separa da a porção mais pesada para constituir o material original des te trabalho. Verifica-se, pela tabela 7, que a passagem do material original (tratamento 1) pela selecionadora eletrônica uma, duas e três vezes, bem como a catação manual com oito pessoas permitiu a obtenção de materiais com pureza física maior que o material original; observa-se, ainda na tabela 7, que a pureza fisica do material descartado pela selecionadora eletrônica foi inferior ao material original; estes dados con cordam com os obtidos por BOYD et alii (1968) que comprovaram a eficiência da seleção eletrônica na melhoria da pureza físi ca das sementes. A presença de sementes sem tegumento, semen tes partidas e torrões de terra separados e descartados pela selecionadora eletrônica contribuiu para a menor porcentagem de pureza do material descartado (tratamento 7).

Como forma de avaliar o grau de danificações mecânicas nas sementes de amendoim nos diferentes tratamentos utilizou-se o exame de sementes com tegumento danificado, observando--se e separando-se as sementes de amendoim com os menores sinais de tegumento rompido; os dados, conforme tabela 8 , mostram que houve diminuição significativa na porcenta gem de sementes com tegumento danificado após a seleção eletrônica com uma, duas e três passagens pela máquina, bem como, pela catação manual com oito pessoas. Observa-se ainda 
que o material descartado pela selecionadora eletrônicà foi significativamente inferior em qualidade ao material original (testemunha) e aos demais tratamentos que envolviam a catação das sementes.

observa-se que durante a seleção eletrônica, ocorriam danificações mecânicas caracterizadas por lesões nos tegumentos das sementes quando estas, após passarem pela câma ra de análise, atingiam as bicas de saída das sementes selecionadas e de material descartado. Sugere-se, assim, que tra balhos sejam realizados, avaliando, com testes apropriados, os danos mecânicos imediatos e latentes que as sementes de amendoim sofrem neste ponto da máquina e se necessário modificações sejam feitas para atenuar estes danos.

A avaliação da qualidade fisiológica das semen tes realizadas pelos testes de germinação, envelhecimento ace lerado, emergência em areia e emergência em campo mostrou a superioridade das sementes tratadas com fungicida em relação as sementes não tratadas em todas as épocas de análise, concordando com os resultados obtidos por BACCHI e CANECCHIO FILHO (19.54), ZINK et alii (1962), TOLEDO e GRANER (1963), CAMPACCI e SILVEIRA FILHO (1964), BELL (1968), LAGO e TOLEDO (19.70) L, CARTER (1973), BELL (1974), BACKMAN e HAMMOND (1976), LAGO et alii (1976), TELLA et alii (1976), SILVEIRA E MARIOTTO (1979), HAMMONS (1980) e MARIOTTO et alii (1982). Este efeito foi decorrente, provavelmente, da manutenção de melhores condições sanitárias das sementes tratadas como sugerem 
BELL (1968), MARIOTTO et alii (1982), e AMARAL e USBERTI (1983) e a proteção exercida pelo fungicida à penetração de fungos, principalmente nas sementes com danos mecânicos como foi veri ficado por CARTER (1973) e BELL (1974).

Com relação a manutenção da qualidade fisiológica, verificou-se acelerada queda no poder germinativo das sementes de amendoim não tratadas após 6 meses (2ạ época) de armazenamento, conforme verificado também por ZINK et alii (1962), LAGO et alii (1976) e TELLA et alii (1976); os testes de envelhecimento acelerado, emergência em areia e emergência em campo atestam a rápida perda de vigor das sementes não tratadas. As sementes que receberam tratamento fungicida, após 6. meses de armazenamento, apresentaram rápida perda de vigor expressos pelos testes de envelhecimento acelerado e emergência em areia, estes resultados contrastam com os obtidos no teste de emergência em campo, onde as sementes tratadas manti veram a porcentagem de emergência com acentuada superioridade sobre as sementes não tratadas.

Acredita-se que as condições ocorridas no teste de emergência em campo com temperatura média de 18,49C e elevada precipitação tenham sido mais favoráveis que as condi çỗes a que as sementes foram expostas nos testes de germinaçäo, emergência em areia e envelhecimento acelerado, o que ex plica o resultado obtido de $74 \%$ de plântulas emergidas durante a 3ạ época de análise para as sementes com tratamento fungicida. Nesta mesma época a eficiência do tratamento fungici 
da persistia conforme dados da tabela 20, para o exame de sanidade de sementes, e os elevados níveis de ocorrência dos fun gos Aspergillus spp, Penicillium spp, e Rhizopus sp nas sementes não tratadas durante o armazenamento refletiram na bai xa percentagem de emergência obtida no campo; não fosse a manifestação dos efeitos destes fungos as sementes não tratadas poderiam ter no campo comportamento semelhante as sementes tratadas.

Durante o armazenamento das sementes a umidade relativa do ar manteve-se próxima aos valores 70 a $80 \%$, com ligeiras variações entre as épocas de análise: assim para a 1a época, a umidade relativa do ar esteve ao redor de 65\% quan do obteve-se $6,2 \%$ de água nas sementes, durante a 2 ạ época, a umidade relativa do ar era de $78 \%$ e obteve-se $7,8 \%$ de ägua na semente e para a 3ạ época, a umidade do ar estava ao redor de 75\% e obteve-se $7,3 \%$ de água nas sementes, conforme apêndice 1 .

De acordo com ZINK et alii. (1962), TANGo et alii (19.71/72); LAGO et alii (1976) e TELLA et alii.(1976), conserva-se adequadamente as sementes de amendoim quando a umidade destạs não ultrapassar 6,5\% o que ocorreu neste trabalho apenas na lạ época de análise. Observa-se:portanto que as sementes apresentaram frequentemente graus de umidade passíveis de exercer efeitos prejudiciais sobre sua qualidade fí siológica, bem como para o desenvolvimento de fungos de armazenamento tais como Aspergillus spp, Penicillium spp e Rhizopus sp. que ocorreram em elevados nỉveis nas sementes não tratia- 
das a semelhança de outros trabalhos (DIENER, 1960, NAKAMURA e NISHIMURA, 1974, MERCER e KISYOMBE, 1978; MARIOTTO et alii, 1982, AMARAL e USBERTI, 1983, MORAES e MARIOTTO, 1984). Considerando-se os efeitos dos métodos de bene ficiamento sobre a qualidade fisiológica das sementes, avaliado pelos testes de germinação, envelhecimento acerelado e emergência em campo verifica-se que o material descartado pela selecionadora eletrônica foi inferior aos demais tratamentos; no entanto, não foram verificadas diferenças estatísticas entre o material original e os demais tratamentos, os quais envolviam a catação das sementes. O fato do material descartado ser de qualidade inferior demonstra que o fundo de contraste e as demais regulagens utilizadas para a separação do material indesejāvel foram adequadas. Por tentativas escolheu-se um fundo de contraste e as regulagens de seleção de claros e escuros que proporcionassem a separação das sementes de amendoim com coloração mais clara e mais escura que a cor característica do cultivar, bem como de sementes com o tegu mento rompido, deixando assim o embrião exposto.

Entretanto, como o material original era de boa qualidade fisiológica, pois já havia sido processado pela mâquina de limpeza e classificação e pela mesa gravitacional, a retirada pela catação manual e/ou eletrônica do material indesejāvel restante, pouca influência exerceu sobre a qualidade fisiológica do lote. Assim confirma-se a necessidade de se avaliar através de um controle de qualidade por testes pre 
liminares, as chances de melhoria dos padrões das sementes an tes de iniciar a despesa de uma catação manual ou uma seleção ëletrônica, como foi observado por DICKENS e WHITAKER (1975) na tentativa de remover sementes de amendoim afetadas pela afla toxina. Observou-se, ainda, que apenas uma catação eletrônica foi suficiente para remover os contaminantes indesejáveis pois não houve efeito de número de catações sobre a qualidade física e fisiológica das sementes. O mesmo foi verificado por LIMA (1980) selecionando eletronicamente sementes de feijão.

Os fungos detectados e identificados no exame de sanidade das sementes (Tabela 20), coincidem com aqueles de ocorrência comum em sementes de amendoim armazenadas, citą dos por DIENER (1960), CARTER (1973), BELL (1974), NAKAMURA e NISHIMURA (1974), MERCER e KISYOMBE (1978), MARIOTTO et alii (1982), AMARAL e USBERTI (1983) e MORAES e MARIOTTO (1984). Os fungos detectados, Aspergillus spp, Penicillium spp e Rhizpus sp são considerados fungos de "armazenamento" e sua ação ocasiona séria perda de viabilidade das sementes, fato este que pode ser comprovado neste trabalho pela superioridade das sementes com tratamento fungicida em relação as não tratadas, nos testes de germinação, envelhecimento acelerado, emergência em areia, emergência em campo e exame de sanidade das sementes.

Verificou-se também que não houve diferenças marcantes entre a sanidade das sementes provenientes dos di- 
ferentes métodos de beneficiamento. Após a assepsia super ficial das sementes observou-se acentuada redução nos níveis de ocorrência de Penicillium spp; se admitir-se o efeito tóxí co do hipoclorito de sódio (1:3) sobre os microrganismos, verifica-se que as sementes estavam infectadas superficialmente pelo fungo Penicillium spp. Este efeito foi observado menos acentuadamente para o fungo Aspergillus spp. Sobre a ocorrên cia do fungo Rhizopus sp observou-se que a assepsia superficial não afetou de forma acentuada os níveis de ocorrência observados nas sementes não tratadas, indicando que $\circ$ fungo Rhizopus sp pode estar localizado mais internamente nas sementes de amendoim.

Considerando-se as sementes não tratadas e com assepsia superficial observou-se que os maiores níveis de Aspergillus spp e Rhizopus sp ocorreram nas sementes descarta das pela selecionadora eletrônica, explicando em parte a menor qualidade fisiológica destas sementes. 
58.

\section{CONCLUSÕES}

De acordo com os dados obtidos nas condições em que foi realizado o trabalho pode-se concluir que a escoIha manual e a seleção eletrônica pela cor permitiram a obten ção de lotes de sementes de amendoim com qualidade física superior, mas não alteraram sua qualidade fisiológica e sanitária.

O material descartado pela selecionadora eletrônica, composto predominantemente de sementes de amendoim de coloração mais clara e mais escura que a cor característica do cultivar e de sementes com tegumento danificado expon do o embrião, foi inferior em qualidade física, fisiológica e sanitäria, entretanto, sua remoção não alterou a qualidade fí siológica e sanitária do lote de sementes.

o tratamento fungicida das sementes de amen doim melhorou sua qualidade fisiológica e sanitária e protegeu a semente no momento da semeadura. 
59.

\section{LITERATURA CITADA}

ALMEIDA, A.M.R. e C.C. MACHADO, 1979. Efeito da uti].ização de sementes manchadas pelo vírus do mosaico comum da soja sobre a emergência, rendimento e porcentagem de sementes colhidas com manchas. Resultados da pesquisa de soja 1978 179 - CNP Soja/EMBRAPA. Londrina, p.165-168.

ALMEIDA, A.M.R. e L.C. MIRANDA, 1979: Ocorrência de vírus do mosaico comum da soja no Estado do Paraná e sua transmissi bilidade pelas sementes. Fitopatologia Brasileira, Brasília, 4 : 293-297.

ALMEIDA, L.D.; E.A. BULISANI; J.A. MAEDA e H.A.A. MASCARENHAS, 1980. Efeito a região de produção e escolha manual, na germinação, emergência e produção de sementes de feijão. Instituto Agronômico, Campinas, Circular 107, 1lp.

AMARAL, H.M. e R. USBERTI, 1983. Deteç̧ão de fungos em semen tes de amendoim (Arachis hypogaea L.) armazenadas com e sem fungicida. III Congresso Brasileiro de Sementes. Resumo dos trabalhos técnicos. ABRATEs, Campinas, p.80.

BACCHI, O. e V. CANECCHIO FILHO, 1954. A desinfecção de sementes de amendoim, Bragantia, Campinas, 18(15): 51-70. 
BACKMAN, P.A. e J.M. HAMMOND, 1976. Germination losses associated with delayed application of seed treatment fungicides after peanut shelling. Plant Disease Reporter, 60 (1) : $1-3$.

BASKIN, C.C. e J.C. DELOUCHE, 1971. Effects of mechanical shelling on storability of peanut (Arachis hypogaea I.) seed. Proc. Ass. Off. Seed Anal. (61): 78-84.

BELL, D.K., 1968. Relationships of peanut seed treatment fun gicides to seed mycoflora and germination and seeding emergence. Plant Disease Report, 52: 240-243.

BELL, D.K., 1974. Effects of mechanical injury, fungi and temperature on peanut seed decay in soil. Phytopatology, $64: 241-243$.

BOYD, A.H.; G.B. WELCH e J.C. DELOUCHE, 1968. Potential aplications of eletric color sorting techniques in seed technology. Journal 1084 of the Mississippi. Agricultural Experiment Station. Mississippi, p.34.

BRADENBURG, N.R. e J.K. PARK, 1977. The principles and practice of seed cleaning: separation with equipment that senses surface texture, colour, resiliense and electrical properties of seeds. Seed Science and Technology, $\underline{5}$ (2): 187-197.

BRASIL; MINISTERIO DA AGRICULTURA, 1976. Regras para Aná-lise de Sementes. Departamento Nacional de Produção Vegetal. Divisão de Sementes e Mudas. Brasília, $188 \mathrm{p}$. 
BRASIL, MINISTERIO DA AGRICULTURA, 1983. Normas para a produção de semente fiscalizada. Delegacia Federal da Agricultura, CESM-CEPROSEM-SP, São Paulo, 83p.

CAMPACCI, C.A. e J.P. SILVEIRA FILHO, 1964. Desinfecção de sementes de amendoim. O Biológico, São Paulo, 30 (12): $320-323$.

CARTER, J.B.H., 1973. The influence of the testa, damage and seed dressing on the emergence of groundnut (Arachis hypogaea L.). Ann. Appl. Biol., 74: 315-323.

CASTRO, P., 1932. Sementes e seu preparo antes do plantio. In: A Semente. Secretaria da Agricultura, Indústria e Comércio do Estado de São Paulo. São Paulo, p.9.

CUNHA, J.M., 1979. Seleção cxomática de sementes de feijão (Phaseolus vulgaris $I$.$) e seus efeitos na produção. Summa$ phytopathologica, Piracicaba, $\underline{5}(1 / 2): 101-106$.

CUNHA, J.M. e A.F.F. OLIVEIRA, 1978. Efeitos da classificação e seleção eletrônica no rendimento e sanidade do feijoeiro. Projeto Fej.jão Relatório 73/75. Epamig. Belo Horizonte, p. $74-79$.

DELOUCHE, J.C., 1965. A preliminary study of methods of sepa rating crimson clover seed on basis of viability. Proceedings Association of Official seed Analyst, 55: 30-36.

DIENER, U.L., 1960. The mycoflora of peanuts in storage. Phy topathology, 50: 220-223. 
DICKENS, J.W. e T.B. WHITAKER, 1975. Efficacy of eletronic color sorting and hand picking to remove aflatoxin contamined kernels from comercial lots of shelled peanuts. Pea nut Science, $\underline{2}(2): 45-50$. In: Oleagineux $\underline{3 l}(2): 92$ (Resumo) .

DYMOND, F.F., 1920. Color characteristics of red clover seed. Proceedings Association of Official Seed Analyst, 12-13 : $30-32$.

EASTMAN, J.F., 1912. A study of red clover seed with relation to color. Agronomy Journal, 4: 91-102.

FURLANI, P.R.; J. SOAVE; N.C. SCHIMIDT E L.E. AZZINI, 1975. Manchas em sementes de arroz. Summa Phytopathologica. Piracicaba, 1(4): 305-307 (Nota cientifica).

GALLI, F.; K. NIMONYIA e F.D. CONCEIÇÃO, 1983. Nematospora coryli Peglion, agente causal da mancha em feijão comum (Phaseolus vulgaris L.). Olericultura. Santa Maria, 3: 14 .

GARREN, K.H. e B.B. HIGGINS, 1947. Fungi associated with run ner peanut seeds and their relation to concealed damage. Phytopathology, 37(7): 512-522.

GARREN, K.H.; B.B. HIGGINS.e J.G. FUTRAL, 1947. Blue black descoloration of Spanish peanuts. Phytopathology, 37 (9): 669 .

GILLIER, P..e P. SILVESTRE, 1970. El cacahuete, o mani. Barcelona, Ed. Blume, 276p. 
GODOY, O.P.; J. MARCOS FILHO e G.M.S. CAMARA, 1982. Tecnologia da produção. In: Câmara, G.M.S.; O.P. Godoy; J. Marcos Filho e H. Fonseca. Amendoim, produção, pré-processamento e transformação agroindustrial. São Paulo, Governo do Estado de São Paulo, 83p. (Série Extensão Agroindustrial, 3) .

GOMES, T.L.L. e O.D. DHINGRA, 1981. Redução de manchas em sementes de feijão vagem (Phaseolus vulgaris $\mathrm{L}$. ) por apli cação ảe fungicidas. Fitopatologia Brasileira, Brasilia, $\underline{6}(3): 594$.

HAMMONS, R.O., 1980. Research and extension imputs resulting on high yields of groundnuts in the U.S.A. In: Proceedings of the Internacional Workshop on Groundnuts. India, ICRISAT, p. 33-39.

KIMATI, H., 1980. Doenças do amendoim. In: Galii, F., Coordenador. Manual de Fitopatologia, doenças dasplantas Cultivadìs. São Paulo, Ed. Agronômica Ceres, voì. 2, p.65-74.

LAGO, A.A. e F.F. TOLEDO, 1970. Tratamento de sementes de amendoim com inseticidas sistêmicos cominados a fungicidas. Anais do II Seminário Brasilejro de Sementes, p.193-198.

LAGO, A.A.; D.B. ORTOLANI; E. ZINK e C.O. EERNANDES; 1976. Efeito de diversos tratamentos fungicidas na longevidade de sementes de amendoim. Semente, Brasilia, 2(2): 26-32.

LIMA, P.R.A., 1980. Efeitos da catação eletrônica pela cor e do tratamento fungicida sobre a qualidade de sementes de feijão (Phaseolus vulgaris L.). Piracicaba, ESALQ/USP. 60p. (Dissertação de Mestrado).

LIMA, E.F.; R.M. VIEIRA e J.M.F.C. CARVALHO, 1984. Influência de Rhizopus sp. Aspergillus niger e A. Glavus na deterioração de sementes de algodoeiro armazenadas. Fitopatolo gia Brasileira, Brasilita, 9 : 555-560. 
LIMA NETO, V.C. e A.S. COSTA, 1976. Eficiência da selecionadora eletrônica na separação de sẹmentes de soja com mancha café. In: Resumos do IX Congresso Anual da Sociedade Brasileira de Fitopatologia, Campinas, p.38.

LOLLATO, M.A. e W.R. SILVA, 19.81. Efeito da utilização da mesa gravitacional na qualidade de sementes do feijoeiro (Phaseolus vulgaris L.). Nota Prévia. II Congresso Bra sileiro de sementes. Resumo dos trabalhos técnicos. ABRATES, Recife, p.19.

MARIOTTO, P.R.; A.P. SILVEIRA; P. FIGUEIREDO; D.A. OLIVEIRA e J.B.M. ARAUJO, 1982. Efeito do tratamento de sementes de amendoim com fungicidas. O Biolögico, São Paulo, 48 (3): $53-6.0$.

MEHTA, Y.R., 1978. Doenças do trigo e seu controle. Piracica ba. Ed. Summa Phytopathologica e Editora Agronômica ceres. $190 p$.

MENEZES, J.R. e S.K. MOHAN, 1982. Efeitn da seleção visual da semente de feijäo (Phaseolus vulgaris $I_{.}$) sobre a quali dade sanitāria. In: Anais da I Reunião Nacional de Pesquisa de Feijão. Goiânia, CNPAF/EMBRAPA, p.343-344.

MENTEN, J.O.M.; W.J. GIACOMEI.LI; A. TULMAN NETO e A. ANDO, 1979. Efeito da mancha de levedura na qualidade de sementes de feijão (Phaseolus vulgaris L.). Fitopatologia Brasileira, 4 : 493-501.

MENTEN, J.O.M.; J.M. SALGADO; G.P. RIOS e P.C.T. CARVALHO, 1977. Aspectos da mancha nematospora em feijão (Phaseolus vulgaris I.) e soja (Glycine max (I.) Merril). Fitopatolo logia Brasileira, Brasilia, 2 : 91. 
MERCER, P.C. e C.J. KISYOMBE, 1978. The fungal flora of groundnut kernels in Malawi and the effect of seed dressing. $\underline{\text { PANS }}, \underline{24}(1): 35-42$.

MORAES, S.A. e P.R. MARIOTTO, 1984. Diagnóstico da patologia de sementes de amendoim no Brasil. In: MENTEN, Coord. Situação e perspectivas da patologia de sementes no Brasil. 10 Simpósio Brasileiro de Patologia de Sementes. ABRATES, Piracicaba, p.95-96.

NAKAMURA, M. e A.M. NISHIMURA, 1974. Fungos associados a má germinação de sementes de amendoim (Arachis hypogaea I.). Cientifica, Jaboticabal, 2 (2): 257 .

NEERGAARD, P. , 1977. Seed Pathology. London, MacMillan Press 2 vol. $839 \mathrm{p}$.

SILVEIRA, A.P. e P.R. MARIOTTO, 1979. Comportamento de alguns fungicidas no controle de fungos responsáveis pelo "damping off" na cultura do amendoim. Summa Phytopathologica. Piracicaba, $\underline{5}(1 / 2)$. p.19.

SMITTLE, D.A.; R.E. WILLIAMSON E J.R. STANSELL, 1976. Response of snap bean to seed separation by aerodynamic propex ties. Hortscience, 11(5): 469-471.

TANGO, J.S.; I.M. NAKAMURA; M.F.F. LEITÃO e B.A. JORDÃO, 1971/72. Influência da umidade relativa do ar na estabili dade do amendoim em grão em armazenamento. Coletânea do Instituto de Tecnologia de Alimentos, Campinas, $\underline{4}$ : 71-82.

TELLA, R.; A.A. LAGO e E. ZINK, 1976. Efeitos de diversos níveis de umidade e do tratamento fungicida na longevida de de sementes de amendoim. Bragantia, Campinas, 35 (2): $335-342$. 
TOLEDO, F.F. e M. GRANER, 1963. Amendoim: tratamento de sementes. Revista de Agricultura. Piracicaba, 38(4): 189195 .

USBERTI, R. , 1982. Relações entre teste de envelhecimento ace lerado, potencial de armazenamento e tamanho de sementes em lotes de amendoim (Arachis hypogaea L.). Revista Brasileira de Sementes, Brasilia, $\underline{4}(1): 31-44$.

VIEIRA, C., 1967. O feijoeiro comum: cultura, doenças e meIhoramento. Viçosa, Imprensa Universitária. 220 p.

WATZ, J., 1928. A semente e sua importância. Secretaria da Agricultura Indístria e Comércio do Estado de são Paulo. São Paulo, p.12-13.

WILSON, C., 1947. Concealed damage of peanut in Alabama. Phy topathology, $37(9): 657-668$.

YORINORI, J.T., 1982. Doenças de Soja. In: Soja no Brasil Central. Campinas, Fundação Cargill, p.301-364.

ZINK, E.; F.J. CORAL e R. TELLA, 1962. Estudo sobre a conservação de sementes de amendoim. Bragantja, Campinas, 21 : CLIX-CLXV. Nota 27 . 
$67:$

A. $\underline{E} \underline{\mathrm{N}} \underline{\mathrm{D}} \mathrm{I} C \underline{\mathrm{E}}$ 
Apêndice 1. Grau de umidade: valores médios do grau de umidade das sementes armazenadas e umidade relativa do ar (\%) no período dos testes. Piracicaba, 1982/83.

\section{Grau de umidade (\%) - Dados originais}

Tratamento

\begin{tabular}{ccc}
\hline $\mathrm{E}_{1}$ & $\mathrm{E}_{2}$ & $\mathrm{E}_{3}$ \\
Out/Nov/82 & $\mathrm{Jan} /$ Fev/83 & Abr/Mai/83
\end{tabular}

\begin{tabular}{cccc}
\hline 1 & 6,1 & 7,7 & 7,1 \\
2 & 6,2 & 7,8 & 7,3 \\
3 & 6,2 & 7,7 & 7,4 \\
4 & 6,1 & 7,8 & 7,4 \\
5 & 6,3 & 7,8 & 7,4 \\
6 & 6,2 & 7,8 & 7,2 \\
7 & 6,2 & 7,7 & 7,2 \\
\hline Média & 6,2 & 7,8 & 7,3 \\
\hline Umidade relativa & & 78 & 75 \\
do ar (\%) no pe- & 65 & & \\
ríodo dos testes & & & \\
\hline
\end{tabular}


Apêndice 2. Dados diários das temperaturas máximas, mínimas e médias $\left({ }^{\circ} \mathrm{C}\right)$ e da precipitação pluvial $(\mathrm{mm})$, no período de $20 / 10 / 82$ a $09 / 11 / 82$ durante a condução do teste de emergência em campo.

\begin{tabular}{|c|c|c|c|c|}
\hline Dia/Mês & $\begin{array}{l}\text { T.Minima } \\
\text { (oc) }\end{array}$ & $\begin{array}{l}\text { T.Máxima } \\
\text { (OC) }\end{array}$ & $\begin{array}{c}\text { T.Média } \\
\text { (oC) }\end{array}$ & $\begin{array}{l}\text { Precipitação } \\
\text { pluvial } \\
\text { (mm) }\end{array}$ \\
\hline $20 / 10$ & 13,0 & 28,0 & 20,9 & 11,2 \\
\hline $21 / 10$ & 17,2 & 32,2 & 24,7 & - \\
\hline $22 / 10$ & 17,2 & 28,2 & 22,7 & - \\
\hline $23 / 10$ & 19,2 & 29,9 & 24,5 & - \\
\hline $24 / 10$ & 19,1 & 32,2 & 25,6 & 1,4 \\
\hline $25 / 10$ & 19,4 & 33,2 & 26,3 & - \\
\hline $26 / 10$ & 19,2 & 32,9 & 22,5 & - \\
\hline $27 / 10$ & 18,0 & 30,6 & 24,3 & 0,5 \\
\hline $28 / 10$ & 19,9 & 33,2 & 26,0 & - \\
\hline $29 / 10$ & 18,4 & 31,0 & 24,7 & 7,7 \\
\hline $30 / 10$ & 19,0 & 31,0 & 25,0 & - \\
\hline $31 / 10$ & 15,4 & 31,0 & 23,2 & - \\
\hline $01 / 11$ & 15,6 & 31,2 & 23,4 & - \\
\hline $02 / 11$ & 18,0 & 32,9 & 25,4 & - \\
\hline $03 / 11$ & 19,6 & 33,2 & 26,4 & - \\
\hline $04 / 11$ & 20,2 & 33,5 & 26,8 & 2,7 \\
\hline $05 / 11$ & 20,0 & 34,9 & 27,9 & 6,0 \\
\hline $06 / 11$ & 18,6 & 31,4 & 25,0 & - \\
\hline $07 / 11$ & 19,2 & 28,4 & 23,8 & - \\
\hline $08 / 11$ & 18,8 & 31,0 & 24,9 & - \\
\hline $09 / 11$ & 19,6 & 32,2 & 25,9 & - \\
\hline Total & - & - & - & 29,5 \\
\hline Média & 18,3 & 31,5 & 24,7 & - \\
\hline
\end{tabular}


Apêndice 3: Dados diários das temperaturas máximas, mínimas e médias ( $\mathrm{oC}$ ) e da precipitação pluvial (m), no pe ríodo de 16/02/83 a 09/03/83 durante a condução do teste de emergência em campo.

\begin{tabular}{|c|c|c|c|c|}
\hline Dia/Mẽs & $\begin{array}{l}\text { T.Mínima } \\
\text { (oC) }\end{array}$ & $\begin{array}{c}\text { T.Māxima } \\
\text { (oc) }\end{array}$ & $\begin{array}{c}\text { T.Média } \\
\text { (OC) }\end{array}$ & $\begin{array}{c}\text { Precipitação } \\
\text { pluvial } \\
\text { (nm) }\end{array}$ \\
\hline $16 / 02$ & 20,0 & 31,1 & 25,5 & - \\
\hline $17 / 02$ & 19,3 & 33,9 & 26,6 & - \\
\hline $18 / 02$ & 20,8 & 34,2 & 27,5 & 1,5 \\
\hline $19 / 02$ & 18,2 & 34,2 & 26,2 & - \\
\hline $20 / 02$ & 18,8 & 34,0 & 26,4 & - \\
\hline $21 / 02$ & 19,6 & 32,9 & 26,2 & - \\
\hline $22 / 02$ & 19,8 & 32,2 & 26,0 & 64,7 \\
\hline $23 / 02$ & 15,4 & 33,2 & 24,3 & - \\
\hline $24 / 02$ & 19,5 & 32,1 & 25,8 & 1,7 \\
\hline $25 / 02$ & 19,5 & 32,4 & 25,9 & - \\
\hline $26 / 02$ & 20,3 & 33,4 & 26,8 & 1,4 \\
\hline $27 / 02$ & 20,4 & 31,2 & 25,8 & 21,3 \\
\hline $28 / 02$ & 18,8 & 31,0 & 24,9 & 3,4 \\
\hline $01 / 03$ & 20,0 & 30,2 & 25,1 & 20,3 \\
\hline $02 / 03$ & 20,8 & 32,4 & 26,6 & 67,5 \\
\hline $03 / 03$ & 19,2 & 30,4 & 24,8 & 1,8 \\
\hline $04 / 03$ & 20,4 & 31,0 & 25,7 & - \\
\hline $05 / 03$ & 21,3 & 31,4 & 26,3 & 18,0 \\
\hline $06 / 03$ & 20,0 & 31,0 & 25,5 & 0,8 \\
\hline $07 / 07$ & 18,4 & 26,9 & 22,6 & 3,3 \\
\hline $08 / 03$ & 18,8 & 24,9 & 21,8 & - \\
\hline $09 / 03$ & 17,9 & 30,2 & 24,0 & - \\
\hline Total & - & - & - & 205,7 \\
\hline Média & 20,3 & 33,0 & 26,6 & - \\
\hline
\end{tabular}


Apêndice 4. Dados diários das temperaturas máximas, mínimas e médias (ọ) e da precipitação pluvial (mm), no pe ríodo de $20 / 05 / 83$ a $16 / 06 / 83$ durante a condução do teste de emergência em campo.

\begin{tabular}{|c|c|c|c|c|}
\hline Dla/Mês & $\begin{array}{l}\text { Mínima } \\
\text { (oC) }\end{array}$ & $\begin{array}{l}\text { T.Máxima } \\
\text { (oC) }\end{array}$ & $\begin{array}{c}\text { T.Média } \\
\text { (oc) }\end{array}$ & $\begin{array}{l}\text { Precipitação } \\
\text { pluvial } \\
\text { (mm) }\end{array}$ \\
\hline $\begin{array}{l}20 / 05 \\
21 / 05 \\
22 / 05 \\
23 / 05 \\
24 / 05 \\
25 / 05 \\
26 / 05 \\
27 / 05 \\
28 / 05 \\
29 / 05 \\
30 / 05 \\
31 / 05 \\
01 / 06 \\
02 / 06 \\
03 / 06 \\
04 / 06 \\
05 / 06 \\
06 / 06 \\
07 / 06 \\
08 / 06 \\
09 / 06 \\
10 / 06 \\
11 / 06 \\
12 / 06 \\
13 / 06 \\
14 / 06 \\
15 / 06 \\
16 / 06\end{array}$ & $\begin{array}{l}14,9 \\
14,2 \\
11,9 \\
12,2 \\
16,0 \\
14,6 \\
13,2 \\
13,2 \\
17,4 \\
14,6 \\
15,0 \\
15,9 \\
14,8 \\
14,0 \\
14,0 \\
13,9 \\
12,6 \\
13,2 \\
13,0 \\
8,8 \\
9,2 \\
16,4 \\
15,4 \\
15,8 \\
14,9 \\
13,4 \\
12,0 \\
7,2\end{array}$ & $\begin{array}{l}29,8 \\
23,0 \\
25,6 \\
26,9 \\
19,2 \\
21,6 \\
22,8 \\
21,0 \\
26,1 \\
24,6 \\
22,2 \\
18,9 \\
20,0 \\
21,6 \\
16,8 \\
19,0 \\
17,9 \\
19,2 \\
15,0 \\
21,2 \\
23,0 \\
25,0 \\
26,1 \\
23,9 \\
28,0 \\
28,0 \\
24,0 \\
21,0\end{array}$ & $\begin{array}{l}22,3 \\
18,6 \\
18,7 \\
19,5 \\
17,6 \\
18,1 \\
18,0 \\
17,1 \\
21,7 \\
19,6 \\
29,7 \\
17,4 \\
17,4 \\
17,8 \\
15,4 \\
16,4 \\
15,2 \\
16,2 \\
14,0 \\
15,0 \\
16,1 \\
20,7 \\
20,7 \\
19,8 \\
21,4 \\
20,7 \\
18,0 \\
14,1\end{array}$ & $\begin{array}{c}- \\
- \\
21,3 \\
60,7 \\
1,1 \\
- \\
- \\
15,6 \\
64,0 \\
36,8 \\
59,0 \\
2,4 \\
6,8 \\
13,1 \\
15,4 \\
13,7 \\
31,8 \\
56,7 \\
- \\
1,9 \\
21,9 \\
- \\
- \\
- \\
- \\
- \\
- \\
-\end{array}$ \\
\hline Total & - & - & - & 422,2 \\
\hline Médias & 13,6 & 22,5 & 18,4 & - \\
\hline
\end{tabular}


Apêndice 5. Unidade relativa do ar, média diária (o), referentes ao am. biente de armazenamento (D.A.H./L.A.S./ESALQ) das sementes de amendoim no período de outubro de 1982 a junho de 1983.

\begin{tabular}{|c|c|c|c|c|c|c|c|c|c|}
\hline Dia & OUT & NOV & $\mathrm{DEZ}$ & JAN & FEV & MAR & $A B R$ & MAI & JUN \\
\hline $\begin{array}{l}01 \\
02 \\
03 \\
04 \\
05 \\
06 \\
07 \\
08 \\
09 \\
10 \\
11 \\
12 \\
13 \\
14 \\
15 \\
16 \\
17 \\
18 \\
19 \\
20 \\
21 \\
22 \\
23 \\
24 \\
25 \\
26 \\
27 \\
28 \\
29 \\
30 \\
31\end{array}$ & $\begin{array}{r}- \\
- \\
- \\
78,0 \\
72,3 \\
74,3 \\
79,3 \\
76,3 \\
- \\
72,5 \\
77,6 \\
82,3 \\
59,6 \\
62,0 \\
68,0 \\
- \\
72,0 \\
65,3 \\
65,0 \\
71,3 \\
68,3 \\
71,0 \\
- \\
60,5 \\
62,6 \\
65,6 \\
66,0 \\
64,3 \\
63,0 \\
59,0\end{array}$ & $\begin{array}{l}61,6 \\
62,0 \\
56,0 \\
55,6 \\
66,0 \\
66,0 \\
69,3 \\
62,3 \\
61,0 \\
64,3 \\
76,0 \\
75,6 \\
72,6 \\
79,0 \\
84,6 \\
73,6 \\
65,0 \\
65,3 \\
66,3 \\
74,0 \\
73,3 \\
77,3 \\
71,0 \\
73,0 \\
71,0 \\
71,0 \\
75,0 \\
75,0 \\
79,0 \\
73,0 \\
-\end{array}$ & $\begin{array}{l}77,0 \\
79,0 \\
66,0 \\
65,0 \\
71,0 \\
78,0 \\
82,0 \\
75,0 \\
67,0 \\
77,0 \\
84,0 \\
88,0 \\
81,0 \\
84,0 \\
86,0 \\
89,0 \\
87,0 \\
83,0 \\
85,0 \\
84,0 \\
83,0 \\
87,0 \\
86,0 \\
70,0 \\
62,0 \\
65,0 \\
70,0 \\
71,0 \\
80,0 \\
81,0 \\
77,0\end{array}$ & $\begin{array}{l}68,0 \\
68,0 \\
74,0 \\
64,0 \\
80,0 \\
86,0 \\
75,0 \\
79,0 \\
79,0 \\
76,0 \\
76,0 \\
77,0 \\
83,0 \\
82,0 \\
83,0 \\
82,0 \\
88,0 \\
93,0 \\
86,0 \\
83,0 \\
75,0 \\
77,0 \\
74,0 \\
72,0 \\
78,0 \\
80,0 \\
76,0 \\
73,0 \\
73,0 \\
79,0 \\
83,0\end{array}$ & $\begin{array}{l}87,0 \\
85,0 \\
85,0 \\
81,0 \\
74,0 \\
69,0 \\
77,0 \\
84,0 \\
82,0 \\
83,0 \\
82,0 \\
81,0 \\
78,0 \\
78,0 \\
70,0 \\
63,0 \\
62,0 \\
64,0 \\
67,0 \\
65,0 \\
69,0 \\
66,0 \\
69,0 \\
71,0 \\
71,0 \\
72,0 \\
74,0 \\
74,0 \\
- \\
- \\
-\end{array}$ & $\begin{array}{l}75,5 \\
78,0 \\
77,3 \\
75,3 \\
74,6 \\
75,3 \\
78,3 \\
80,6 \\
76,0 \\
67,0 \\
66,0 \\
68,0 \\
70,0 \\
69,3 \\
67,3 \\
65,3 \\
68,0 \\
66,0 \\
71,3 \\
69,0 \\
74,0 \\
74,0 \\
71,6 \\
64,6 \\
65,0 \\
66,3 \\
70,0 \\
75,0 \\
75,0 \\
71,6 \\
71,3\end{array}$ & $\begin{array}{r}72,0 \\
70,6 \\
69,3 \\
70,0 \\
73,3 \\
79,0 \\
75,6 \\
72,6 \\
71,0 \\
71,0 \\
74,0 \\
75,3 \\
76,3 \\
69,7 \\
75,3 \\
75,6 \\
74,3 \\
77,0 \\
74,0 \\
76,0 \\
76,7 \\
73,7 \\
72,3 \\
76,7 \\
83,3 \\
83,3 \\
81,3 \\
82,7 \\
74,3 \\
73,3 \\
-\end{array}$ & $\begin{array}{l}72,6 \\
71,3 \\
69,3 \\
69,0 \\
68,3 \\
67,0 \\
69,3 \\
71,3 \\
75,3 \\
75,0 \\
75,0 \\
74,3 \\
80,0 \\
79,0 \\
78,3 \\
72,6 \\
77,0 \\
74,3 \\
74,3 \\
75,6 \\
75,0 \\
76,3 \\
89,0 \\
89,0 \\
80,0 \\
80,0 \\
81,0 \\
87,0 \\
87,0 \\
94,0 \\
96,0\end{array}$ & $\begin{array}{r}88,0 \\
88,0 \\
94,0 \\
88,0 \\
92,0 \\
95,0 \\
91,0 \\
91,0 \\
98,0 \\
91,0 \\
89,0 \\
89,0 \\
80,0 \\
77,0 \\
69,0 \\
66,0 \\
71,0 \\
70,0 \\
68,0 \\
68,0 \\
65,0 \\
66,0 \\
69,0 \\
71,0 \\
77,0 \\
79,0 \\
82,0 \\
81,0 \\
79,0 \\
78,0 \\
-\end{array}$ \\
\hline
\end{tabular}

Média $\quad 69,0,70,0 \quad 78,0 \quad 78,0 \quad 74,0 \quad 72,0 \quad 75,0 \quad 77,5 \quad 80,0$ 
Apêndice 6. Temperatura: média diária (OC), referentes ao ambiente de armazenamento (D.A.H./L.A.S./ESALQ) das sementes de amendoim, no período de outubro de 1982 a junho de 1983.

\begin{tabular}{|c|c|c|c|c|c|c|c|c|c|}
\hline Dia & OUT & NOV & DEZ & JAN & FEV & MAR & $\mathrm{ABR}$ & MAI & JUN \\
\hline $\begin{array}{l}01 \\
02 \\
03 \\
04 \\
05 \\
06 \\
07 \\
08 \\
09 \\
10 \\
11 \\
12 \\
13 \\
14 \\
15 \\
16 \\
17 \\
18 \\
19 \\
20 \\
21 \\
22 \\
23 \\
24 \\
25 \\
26 \\
27 \\
28 \\
29 \\
30 \\
31\end{array}$ & $\begin{array}{r}- \\
- \\
- \\
- \\
25,0 \\
24,3 \\
22,8 \\
22,6 \\
21,9 \\
- \\
23,3 \\
23,0 \\
22,5 \\
21,8 \\
22,5 \\
21,9 \\
- \\
24,0 \\
23,8 \\
25,7 \\
25,1 \\
24,8 \\
25,2 \\
29,5 \\
26,5 \\
26,6 \\
26,5 \\
26,5 \\
26,1 \\
24,5\end{array}$ & $\begin{array}{l}27,0 \\
27,7 \\
29,1 \\
28,8 \\
26,9 \\
25,5 \\
26,5 \\
27,9 \\
28,2 \\
27,2 \\
24,1 \\
23,5 \\
24,4 \\
22,6 \\
22,9 \\
23,8 \\
24,0 \\
25,8 \\
25,8 \\
25,9 \\
25,9 \\
26,1 \\
26,7 \\
26,0 \\
27,4 \\
26,4 \\
25,9 \\
25,9 \\
23,8 \\
26,4 \\
- \\
25\end{array}$ & $\begin{array}{l}26,1 \\
24,7 \\
20,0 \\
21,3 \\
23,0 \\
23,7 \\
23,3 \\
23,0 \\
23,3 \\
23,6 \\
23,0 \\
23,3 \\
23,7 \\
24,3 \\
24,2 \\
23,3 \\
23,0 \\
23,8 \\
24,2 \\
24,0 \\
24,1 \\
24,1 \\
23,6 \\
24,3 \\
24,7 \\
25,0 \\
23,0 \\
25,2 \\
24,5 \\
24,4 \\
25,0\end{array}$ & $\begin{array}{l}25,8 \\
25,7 \\
25,7 \\
26,1 \\
24,2 \\
24,5 \\
24,7 \\
24,9 \\
25,2 \\
26,7 \\
27,8 \\
26,3 \\
25,3 \\
24,9 \\
24,7 \\
24,4 \\
23,6 \\
24,3 \\
25,3 \\
25,1 \\
25,3 \\
25,4 \\
26,3 \\
25,3 \\
25,3 \\
25,2 \\
25,9 \\
26,2 \\
26,4 \\
26,1 \\
24,9\end{array}$ & $\begin{array}{r}23,6 \\
21,7 \\
22,4 \\
24,5 \\
25,6 \\
26,0 \\
24,8 \\
24,4 \\
24,2 \\
24,6 \\
25,7 \\
25,6 \\
26,1 \\
25,7 \\
26,3 \\
26,9 \\
27,8 \\
27,0 \\
25,9 \\
26,9 \\
25,4 \\
27,5 \\
26,4 \\
25,8 \\
26,4 \\
26,5 \\
25,1 \\
25,0 \\
- \\
- \\
- \\
- \\
-\end{array}$ & $\begin{array}{l}27,5 \\
26,9 \\
26,5 \\
26,6 \\
26,9 \\
25,4 \\
24,1 \\
24,5 \\
25,8 \\
27,2 \\
27,7 \\
26,9 \\
25,8 \\
24,5 \\
24,7 \\
24,7 \\
26,2 \\
26,8 \\
25,5 \\
22,9 \\
21,6 \\
23,3 \\
23,6 \\
23,0 \\
23,5 \\
23,6 \\
23,3 \\
23,6 \\
23,2 \\
24,4 \\
24,5\end{array}$ & $\begin{array}{r}25,4 \\
25,6 \\
25,4 \\
25,6 \\
25,9 \\
24,5 \\
22,8 \\
22,3 \\
22,6 \\
23,3 \\
23,8 \\
22,9 \\
23,3 \\
23,8 \\
23,7 \\
23,9 \\
24,4 \\
25,5 \\
25,7 \\
25,0 \\
24,7 \\
22,3 \\
22,4 \\
21,4 \\
21,9 \\
21,7 \\
22,7 \\
23,0 \\
24,0 \\
24,4 \\
-\end{array}$ & $\begin{array}{l}24,9 \\
25,3 \\
24,7 \\
24,3 \\
24,3 \\
24,1 \\
23,6 \\
22,8 \\
23,0 \\
23,9 \\
23,7 \\
24,3 \\
23,2 \\
22,9 \\
23,3 \\
24,0 \\
22,8 \\
23,0 \\
23,0 \\
21,7 \\
20,8 \\
20,8 \\
20,3 \\
19,9 \\
19,4 \\
19,0 \\
19,9 \\
20,3 \\
19,2 \\
18,4 \\
18,6\end{array}$ & $\begin{array}{l}18,6 \\
17,4 \\
17,7 \\
16,5 \\
16,4 \\
15,6 \\
16,1 \\
16,1 \\
18,2 \\
19,0 \\
19,3 \\
20,3 \\
20,3 \\
19,6 \\
17,6 \\
16,4 \\
16,8 \\
18,1 \\
18,5 \\
19,3 \\
20,2 \\
20,3 \\
20,9 \\
21,1 \\
20,3 \\
19,9 \\
20,0 \\
19,3 \\
18,3 \\
18,1 \\
-\end{array}$ \\
\hline Média & 24,4 & 25,9 & 23,8 & 25,4 & 25,5 & 25,0 & 23,8 & 22,2 & 18,5 \\
\hline
\end{tabular}

